\title{
THEORETICAL INVESTIGATION ON VARIABLE-DENSITY SPRAYS
}

\author{
A. de Risi, T. Donateo, and D. Laforgia \\ Dipartimento di Ingegneria dell'Innovazione, Università di Lecce, Lecce, Italy
}

\begin{abstract}
The aim of the present investigation is the analysis of the influence of liquid-fuel compressibility on the simulation of sprays produced by high-pressure injection systems. Two different equations have been introduced in the KIVA3V code to calculate liquid-phase density. The first one determines fuel density by using a second-order function of drop temperature and pressure, while the second one also takes into account the quantity of air dissolved in the fuel. Breakup, vaporization, and collision models as well as the energy, momentum, and air-spray mass exchange equations were modified so that each droplet would have a different density, according to its position and evolution.

A comparison between experimental and numerical data for sprays injected in a constant-volume vessel at ambient temperature and pressure has been carried out to test the practical capability of the modified KIVA3V subroutines. The predicted and measured results of penetration versus time and drop size distribution showed good agreement. An in-depth study of the influence of gas temperature on the droplet vaporization rate has been performed for a single droplet and for sprays injected in a high-temperature, medium-pressure, constant-volume chamber. The effect of fuel density variability on vaporizing noncombusting sprays has been investigated for both models. The air dissolved in the fuel was found to affect liquid-phase density only at low ambient pressure.

Finally, the experimental data measured on a small-bore diesel engine have been used to verify the provisional capabilities of constant-and variable-density models. NO and soot predictions have shown to be dependent on the model used for liquid-phase density.
\end{abstract}

\section{INTRODUCTION}

A $n$ accurate simulation of the vaporization process is a very important issue for engine investigations, because the gas- phase temperature and the amount of fuel vapor available for combustion are affected by the vaporization rate. $M$ any effects should be considered in the case of dense sprays, such as droplet-droplet and droplet-gas interactions, which influence drop size distribution and vaporization rate.

In the present research, the KIVA $3 \mathrm{~V}$ code has been used to test the effect of fuel density variability on droplet collisions, spray-gas mass and energy exchanges, vaporization process, liquid internal energy, and droplet size distribution. Fuel-air mixing rate and burning rate are known to be dependent on the ratio of ambient density to injected fuel density [13]. Thus, the effect of fuel density is expected to be more important for evaporating sprays injected into relatively low ambient density.

In the KIVA 3V code $[17,19]$, sprays are represented with a set of parcels, with each parcel consisting of a certain number of drops. T he drops contained in one parcel have the same thermodynamic and physical properties, such as temperature, radius, local position, velocity, etc. They differ from parcel to parcel. 0 nly fuel liquid density is considered con-

The authors would like to thank Prof. R. D. R eitz for the comments and suggestions which originated the present study. 


\begin{tabular}{|c|c|c|c|}
\hline \multicolumn{4}{|c|}{ NOMENCLATURE } \\
\hline$a$ & parent drop radius & $W$ & turbulent energy source \\
\hline$b$ & impact parameter & We & W eber number \\
\hline$B$ & mass transfer number & $x$ & drop position vector \\
\hline$b_{\mathrm{cr}}$ & critical impact parameter & y & droplet distortion from sphericity \\
\hline$C_{d}$ & drag coefficient & $Y$ & droplet distortion rate of change \\
\hline$c_{l}$ & liquid specific heat & $\Delta t$ & time step \\
\hline $\begin{array}{l}D_{m} \\
D_{p}\end{array}$ & $\begin{array}{l}\text { mass diffusivity of fuel in air } \\
\text { particle drag function }\end{array}$ & $\mathrm{K}$ & wave number \\
\hline$f^{p}$ & droplet distribution function & $\Lambda$ & wavelength \\
\hline $\mathrm{F}$ & drop velocity rate of change & $\mu$ & dynamic viscosity \\
\hline g & acceleration of gravity & $\rho$ & density \\
\hline$H$ & enthalpy per unit mass & $\sigma$ & liquid surface tension \\
\hline$H_{\text {lat }}$ & latent heat of vaporization & $\tau$ & breakup time \\
\hline$I$ & internal energy per unit mass & $\Omega$ & wave growth rate \\
\hline $\begin{array}{l}i 4 \\
i 4 m\end{array}$ & $\begin{array}{l}\text { computational cell } \\
\text { momentum cell }\end{array}$ & $\chi$ & mass fraction \\
\hline $\begin{array}{l}M \\
\mathrm{mf}_{\text {inj }} \\
N\end{array}$ & $\begin{array}{l}\text { mass in the momentum cell } \\
\text { total injected fuel mass } \\
\text { number of collisions }\end{array}$ & & Subscripts \\
\hline$N_{p}$ & number of drops in the parcel $p$ & 1 & larger drop \\
\hline $\mathrm{O} h$ & O hnesorge number $\left.=\left(\mathrm{We}_{p}\right)\right)^{0.5} / \mathrm{Re}_{p}$ & 2 & smaller drop \\
\hline$p$ & pressure & $a$ & air \\
\hline$P_{\text {vap }}$ & vapor pressure & $d$ & droplet \\
\hline$Q$ & heat transferred & $f$ & fuel mixture \\
\hline$\tilde{Q}_{d}$ & rate of heat conduction to the drop & l & liquid phase \\
\hline$r$ & drop radius & $p$ & parcel of drops \\
\hline$R$ & droplet radius rate of change & $q$ & new drops \\
\hline$R^{*}$ & universal constant of gases & $v$ & vapor phase \\
\hline $\mathrm{Re}$ & Reynolds number & & \\
\hline$r_{\text {noz }}$ & nozzle radius & & \\
\hline Sc & Schmidt number & & Superscripts \\
\hline Sh & Sherwood number & & \\
\hline$t$ & time & $A$ & values at the end of phase $A$ \\
\hline$T$ & temperature & $B$ & values at the end of phase $B$ \\
\hline $\mathrm{tn}_{\text {parc }}$ & total number of injected parcels & $n$ & value at the previous time step \\
\hline u & gas velocity vector & $s$ & spray \\
\hline $\mathrm{u}^{\prime}$ & gas turbulent velocity vector & $"$ & updated quantities after breakup and col- \\
\hline $\mathbf{v}$ & drop velocity vector & & lision calculations \\
\hline V & cell volume & & \\
\hline
\end{tabular}

stant, and its value is assigned in the fuel library subroutine. In particular, the density of $\mathrm{C}_{14} \mathrm{H}_{30}$ is $\rho_{f}=762.55 \mathrm{~kg} / \mathrm{m}^{3}$, and the density of gas oil is $\rho=824 \mathrm{~kg} / \mathrm{m}^{3}$. Therefore, parcels which have different temperature and different pressure have, in the original code, the same density. $M$ any researchers have found [1-6] that fuel density influences the structure and the evolution of sprays by affecting tip penetration, spray angle, and vaporization rate.

$M$ oreover, fuel density is known to be very important in the heat-up period of drops because it increases the drop radius during that period and modifies the surface-mass ratio [7]. Priem et al. [8] developed a spray simulation model that takes into account fuel density variability versus temperature. G onzales et al. [7] compared the KIVA 3V evaporation 
model with Priem's theory and found that KIVA $3 \mathrm{~V}$ predicts a longer droplet lifetime under all conditions of drop size, injection velocity, gas temperature, and pressure. 0 ther vaporization models have been devel oped to consider multicomponent droplets [9] or heterogeneous temperature distribution inside the droplet [10]; many of them assumed that fuel density variability was negligible. M oreover, the lowering of average fuel density due to the cavitation phenomenon, should be considered, as shown by Verhoeven et al. [11]. $\mathrm{H}$ ublin et al. [12] found that, except for $\mathrm{N} \mathrm{O}_{x^{\prime}}$ the lowest emissions are obtained with lowdensity fuels in the case of light-duty diesel engines.

The effect of fuel density variability on the prediction of soot and $\mathrm{NO}$ emissions of a high-speed, small-bore, last-generation diesel engine has been tested for different operating conditions.

\section{NUMERICAL MODELS}

As reported by Ficarella [14], all combustible oils have the same thermodynamics behavior (i.e., the same density-pressure-temperature dependence), which can be represented by the following expression:

$$
\rho_{l}(T, p)=\rho_{0}\left(T, p_{0}\right)\left[1+a(T) p+b(T) p^{2}\right]
$$

where $a(T)$ and $b(T)$ are second-order functions of temperature given by $a(T)=a_{0}+a_{1} T+$ $a_{2} T^{2}, b(T)=b_{0}+b_{1} T+b_{2} T^{2} ; \rho_{0}\left(T, p_{0}\right)$ is the fuel density at temperature $T$ and atmospheric pressure $p_{0}$, which can be calculated as

$$
\rho_{0}\left(T, p_{0}\right)=\rho_{\text {ref }} \cdot \exp \left(\beta T_{\text {ref }}\right) \cdot \exp (-\beta T)
$$

The coefficients in E qs. (1) and (2) are listed in Table 1.

Equation (1) was also used by A rcoumanis et al. [15] to consider density change with pressure in the simulation of fuel injection systems for direct-injection (DI) diesel engines.

Fuel recirculation is usual practice in automotive injection systems and produces a certain amount of air to be trapped in the liquid as microbubbles; this is a noteworthy issue because the presence of dissolved air has been observed to affect fuel density for pressure lower than $2.0 \mathrm{M} \mathrm{Pa}$.

The effect of air can be considered by using the following equation:

Table 1 C oefficients for Fuel D ensity C orrelation

\begin{tabular}{ccccc}
\hline Eq. & Coeff. & $i=0$ & $i=1$ & $i=2$ \\
\hline$(1)$ & $a_{i}$ & $-3.7175 \times 10^{-10} \mathrm{~m}^{2} / \mathrm{N}$ & $5.39464 \times 10^{-10} \mathrm{~m}^{2} / \mathrm{N} \cdot \mathrm{K}$ & $-6.88769 \times 10^{-10} \mathrm{~m}^{2} / \mathrm{N} \cdot \mathrm{K}^{2}$ \\
$(1)$ & $b_{i}$ & $6.18626 \times 10^{-18} \mathrm{~m}^{2} / \mathrm{N}$ & $-2.56408 \times 10^{-10} \mathrm{~m}^{2} / \mathrm{N} \cdot \mathrm{K}$ & $3.11703 \times 10^{-23} \mathrm{~m}^{2} / \mathrm{N} \cdot \mathrm{K}$ \\
$(2)$ & - & $\rho_{\text {ref }}=850 \mathrm{~kg} / \mathrm{m}^{3}$ & $T_{\text {ref }}=293.1 \mathrm{~K}$ & $\beta=72 \times 10^{-5} \mathrm{~K}-1$ \\
\hline
\end{tabular}




$$
\rho_{l}\left(T, p, \chi_{a}\right)=\frac{1}{\frac{1}{\rho_{l}(T, p)}-\chi_{a} \cdot\left(\frac{1}{\rho_{l}(T, p)}-\frac{1}{\rho_{a}(T, p)}\right)}
$$

where $\rho_{l}(T, p)$ is calculated from E q. (1) and $\chi_{a}$ is the mass fraction of air.

The presence of air also affects the calculation of fuel internal energy, which in this case has to be evaluated according to the following equation:

$$
I_{l}\left(p, T, \chi_{a}\right)=I_{l}(p, T)-\chi_{a}\left[I_{l}(p, T)-I_{a}(p, T)\right]
$$

It should be noticed that Eqs. (3) and (4) are written under the hypothesis of negligible molecular interactions between oil and dissolved air, and of negligible surface tension of the air bubbles.

The air mass fraction has been calculated by measuring the sound velocity through the fuel, and a value of $7.4 \times 10^{-3} \%$ (5\% in volume) was found by I shihara et al. [16] for ambient temperature and pressure. This value was found to affect only wave propagation, while mass flow rate and vaporization rate under steady-state conditions were not influenced.

TheK IVA 3 V code calculates liquid-phase internal energy from the values of the vaporphase internal energy, which is assumed to be a function of temperature only. Thus, the actual value of liquid-phase internal energy is calculated at a given droplet temperature $T$ by

$$
H_{l}(T)=H_{v}(T)-H_{\text {lat }}(T)
$$

W hen fuel density is not constant [see E q. (1)], liquid internal energy does not depend on temperature only, but is also affected by the local value of pressure. U sing the definition of enthal py, its expression is given by

$$
I_{l}(T, p)=I_{v}(T)+R^{*} T-H_{\text {lat }}(T)-\frac{p_{\text {vap }}(T)}{\rho_{l}(T, p)}
$$

If the presence of dissolved air is considered, fuel internal energy can be calculated with the following equation:

$$
I_{f}\left(T, p, \chi_{a}\right)=I_{l}(T, p)-\chi_{a} \cdot\left[I_{l}(T, p)-I_{a}(T, p)\right]
$$

where $\rho_{l}(T, p)$ in Eq. (6) is replaced by $\rho_{l}\left(T, p, \chi_{a}\right)$.

As liquid-phase internal energy depends on the actual values of pressure and temperature, it has to be calculated for each parcel separately. This was performed by using drop temperature and pressure (i.e., the value of the pressure in the computational cell that contains the parcel under consideration). 
In the case of two-phase flows, the conservation equations include terms due to the exchange of mass, momentum, and energy between the liquid and gas phases. In the case of sprays, these terms are obtained by summing the rates of changes of mass density [ $\mathrm{E} \mathrm{q}$. (8)], momentum [E q. (9)], internal energy [E q. (10)], and turbulent kinetic energy [E q. (11)] of all droplets at a given position $\mathrm{x}$ and time $t$. The distribution of drop sizes, velocities, and temperatures is accounted for by using a droplet distribution function $f$.

$$
\begin{gathered}
\frac{d \rho^{s}}{d t}=-\int f \rho_{d} 4 \pi r^{2} R d v \cdot d r \cdot d T_{d} \cdot d y \cdot d Y \\
\frac{d \mathbf{F}^{s}}{d t}=-\int f \rho_{d}\left[\frac{4}{3} \pi r^{3} \cdot \frac{d(\mathbf{F}-\mathbf{g})}{d t}+4 \pi r^{2} R \mathbf{v}\right] \cdot d \mathbf{v} \cdot d r \cdot d T_{d} \cdot d y \cdot d Y \\
\frac{d Q^{s}}{d t}=-\int f \rho_{d}\left\{4 \pi r^{2} R\left[I_{l}\left(T_{d}\right)+\frac{1}{2}(\mathbf{v}-\mathbf{u})^{2}\right]\right. \\
\left.+\frac{4}{3} \pi r^{3}\left[c_{l} \cdot \frac{d T_{d}}{d t}+(\mathbf{F}-\mathbf{g}) \cdot\left(\mathbf{v}-\mathbf{u}-\mathbf{u}^{\prime}\right)\right]\right\} \cdot d v \cdot d r \cdot d T_{d} \cdot d y \cdot d Y \\
\frac{d W^{s}}{d t}=-\int f \rho_{d} \frac{4}{3} \pi r^{3}(\mathbf{F}-\mathbf{g}) \cdot \mathbf{u}^{\prime} d v \cdot d r \cdot d T_{d} \cdot d y \cdot d Y
\end{gathered}
$$

The previous equations are discretized both in space and time as detailed in the A ppendix.

\section{Collision Model}

In the KIVA 3V code, two colliding drops can either coalesce or separate; drops coalesce when the impact parameter $b$ is less than the critical value $b_{\text {cr }}$ given by [18]

$$
b_{\mathrm{cr}}=\left(r_{1}+r_{2}\right)^{2} \cdot \min \left[1.0,2.4 f(\gamma) / \mathrm{W} \mathrm{e}_{p}\right]
$$

where

$$
\begin{gathered}
f(\gamma)=\gamma^{3}-2.4 \gamma^{2}+2.7 \gamma \quad \gamma=\frac{r_{1}}{r_{2}} \quad W e_{p}=\frac{\rho_{p}\left|\mathbf{v}_{1}-\mathbf{v}_{2}\right| r_{1}}{\sigma\left(\bar{T}_{p}\right)} \\
\bar{T}_{p}=\frac{T_{1} r_{1}^{3} \rho_{1}+T_{2} r_{2}^{3} \rho_{2}}{r_{1}^{3} \rho_{1}+r_{2}^{3} \rho_{2}}
\end{gathered}
$$

Typically, two colliding parcels have different temperatures and consequently different densities. Thus, when considering the coalescence between parcel 1 and parcel $2\left(r_{1}>r_{2}\right)$, the radius of the resulting droplets is calculated by a mass- weighted average value: 


$$
r_{q}=\sqrt[3]{r_{1}^{3} \frac{\rho_{1}}{\rho_{q}}+N_{c} r_{2}^{3} \frac{\rho_{2}}{\rho_{q}}}
$$

where $N_{c}$ is the number of coalescences for parcel 1 and is calculated according to 0 'R ourke [18].

M oreover, the new droplet velocity and temperature are to be evaluated with a massweighted average procedure that takes into account the different parcel densities. Their values are given by

$$
\begin{gathered}
\mathbf{v}_{q}=\frac{\mathbf{v}_{1} r_{1}^{3} \rho_{1}+\mathbf{v}_{2} r_{2}^{3} \rho_{2} N_{c}}{r_{1}^{3} \rho_{1}+r_{2}^{3} \rho_{2} N_{c}} \\
T_{q}=\frac{T_{1} r_{1}^{3} \rho_{1}+T_{2} r_{2}^{3} \rho_{2} N_{c}}{r_{1}^{3} \rho_{1}+r_{2}^{3} \rho_{2} N_{c}}
\end{gathered}
$$

In the case of grazing collision, drops keep the same radius and their velocities after collisions are calculated by applying the conservation of linear and angular momentum as well as energy conservation [17]. In the frame of reference used by the KIVA 3V code [19], the upgraded droplet velocities can be calculated, under the hypothesis of spherical drops and variable fuel density, with the following equations:

$$
\begin{aligned}
& \mathbf{v}_{1 q}=\frac{\mathbf{v}_{1} r_{1}^{3} \rho_{1}+\mathbf{v}_{2} r_{2}^{3} \rho_{2}+\left(\mathbf{v}_{1}-\mathbf{v}_{2}\right) r_{2}^{3} \rho_{2} Z}{r_{1}^{3} \rho_{1}+r_{2}^{3} \rho_{2}} \\
& \mathbf{v}_{2 q}=\frac{\mathbf{v}_{1} r_{1}^{3} \rho_{1}+\mathbf{v}_{2} r_{2}^{3} \rho_{2}+\left(\mathbf{v}_{2}-\mathbf{v}_{1}\right) r_{1}^{3} \rho_{1} Z}{r_{1}^{3} \rho_{1}+r_{2}^{3} \rho_{2}}
\end{aligned}
$$

where

$$
Z=\frac{b-b_{\text {crit }}}{r_{1}+r_{2}-b_{\text {crit }}}
$$

\section{Vaporization Model}

D ue to the heat exchange with the surrounding gas, droplets warm up and vaporize. D roplet temperature and mass exchanges are calculated [20] by solving the energy and mass conservation equations in L agrangian form, which follows for the reader's convenience.

$M$ ass conservation gives

$$
-\frac{1}{3 r_{p}{ }^{2}} \cdot \frac{d}{d t}\left(\rho_{p} r_{p}^{3}\right)=\frac{\rho_{a} D_{m} B \cdot S h}{2 r_{p}}
$$


where

$$
\mathrm{Sh}=\left(2+0.6 \cdot \mathrm{Re}_{d}^{1 / 2} \cdot \mathrm{Sc}^{1 / 3}\right) \cdot \frac{\ln (1+B)}{B}
$$

is the Sherwood number.

Energy conservation gives

$$
\rho_{p} \frac{4}{3} \pi \cdot r_{p}^{3} c_{l} \cdot \frac{d T_{p}}{d t}-\frac{d}{d t}\left(\frac{4}{3} \pi \rho_{p} r_{p}^{3}\right) \cdot H_{\text {lat }}\left(T_{p}\right)=4 \pi r_{p}^{2} Q_{d}
$$

E quations (18) and (19) can be rearranged as

$$
\rho_{p} \frac{4}{3} \pi \cdot r_{p}^{3} c_{l} \cdot \frac{d T_{p}}{d t}-2 \pi \cdot \rho_{a} D_{m} B \cdot \mathrm{Sh} \cdot r_{p} \cdot H_{\text {lat }}\left(T_{p}\right)=4 \pi r_{p}^{2} Q_{d}
$$

E quation (20) was used to calculate drop temperature rate of change due to heat and mass exchanges.

To integrate Eq. (18), fuel density and mass transfer number were assumed to be linearly dependent on time during the computational time step $\Delta t$. Thus:

$$
\left.\begin{array}{l}
\rho_{p}(t)=\rho_{p}\left(t_{0}\right)+m t \\
B(t)=B\left(t_{0}\right)+B_{m} t
\end{array}\right\} \quad \text { for } \quad t \in\left[t_{0}, t_{0}+\Delta t\right]
$$

where $m$ and $B_{m}$ are defined as

$$
\begin{gathered}
m=\frac{\rho_{p}\left(t_{0}+\Delta t\right)-\rho_{p}\left(t_{0}\right)}{\Delta t} \\
B_{m}=\frac{B\left(t_{0}+\Delta t\right)-B\left(t_{0}\right)}{\Delta t}
\end{gathered}
$$

M oreover, by assuming that

$$
k=\frac{\rho_{a} D_{m} \cdot S h}{2}=\text { const }
$$

during the time step $\Delta t$, Eq. (18) becomes 


$$
3 \rho_{p}(t) \cdot r_{p}(t) \cdot \frac{d r_{p}}{d t}+3 m \cdot\left[r_{p}(t)\right]^{2}+k B(t)=0
$$

T his equation represents the droplet radius rate of variation and allows the calculation of the new drop radius. By integrating Eq. (24) with E q. (21), the value of droplet radius is given by

$$
\begin{gathered}
r_{p}^{2}(t)=\frac{1}{\left(\rho_{p}\left(t_{0}\right)+m t\right)^{2 / 3}} \cdot \frac{2}{3 \cdot 10 m^{2}} \cdot\left\{-9 k\left[\rho_{p}\left(t_{0}\right)+m t\right]^{2 / 3}\right. \\
\times\left[5 B\left(t_{0}\right) \cdot m+2 B_{m} \cdot m \cdot t-3 B_{m} \rho_{p}\left(t_{0}\right)\right]+3\left[\rho_{p}\left(t_{0}\right)\right]^{2 / 3} \\
\left.\times\left[15 B\left(t_{0}\right) \cdot m \cdot k-9 B_{m} \cdot k \cdot \rho_{p}\left(t_{0}\right)+5 m^{2} \cdot r_{p}^{2}\left(t_{0}\right)\right]\right\}
\end{gathered}
$$

where $r_{p}\left(t_{0}\right)=r_{0}$ is the initial droplet radius (i.e., the value of radius calculated at the previous time step).

In the original KIVA 3V code [17], droplet radius was calculated according to the following expression:

$$
r_{p}^{2}(t)=r_{p}^{2}\left(t_{0}\right)-\frac{B\left(t_{0}\right)+B(t)}{2} \cdot \frac{k \cdot t}{\rho_{f}}
$$

It is interesting to note that Eq. (26) is obtained by Eq. (25) in the limit of $m \rightarrow 0$ (i.e., constant fuel density).

By using E q. (25), the drop radius increase due to the heating of the liquid phase, which affects the vaporization rate by changing the volume-to-surface ratio, can be also predicted.

\section{Injection Model}

A stochastic approach similar to that of D ukowicz [21] was used to perform liquid injection. Injected fuel is simulated as parcels of big drops, or "blobs," having a radius equal to the effective nozzle radius. All injected parcels have the same velocity, the same thermodynamic properties, the same initial mass, and therefore the same number of blobs. The initial mass is calculated by using Eq. (27), and the number of drops or "blobs" in each parcel is given by E q. (28):

$$
p m_{\mathrm{inj}}=\frac{m f_{\mathrm{inj}}}{t n_{\text {parc }}}
$$




$$
n_{0}=\frac{p m_{\text {inj }}}{\frac{3}{4} \pi \rho_{l}\left(r_{\mathrm{noz}}\right)^{3}}
$$

The number of parcels injected in the unit time is determined from the measured mass flow rate.

\section{Breakup Model}

A fter injection, blobs undergo a breakup process that removes mass from the blobs and forms new child drops, whose radius $r$ can be predicted by using the stability analysis of cylindrical liquid surfaces perturbed by an axisymmetric displacement [22, 23]:

$$
\begin{gathered}
r=B_{0} \Lambda \quad \text { if } \quad B_{0} \Lambda \leq a \\
r=\min \left[\left(\frac{3 \pi a^{2} u}{(2 \Omega)}\right)^{0.33},\left(\frac{3 a^{2} \Lambda}{4}\right)^{0.33}\right] \quad \text { if } \quad B_{0} \Lambda>a
\end{gathered}
$$

where $B_{0}$ is a constant equal to 0.61 and $a$ indicates the "blob" radius whose rate of change due to breakup is assumed to be equal to

$$
\frac{d a}{d t}=-\frac{(a-r)}{\tau}
$$

where $\tau=3.726 B_{1} a / \Delta \Omega$ and $B_{1}$ is an adjustable constant that depends on the nozzle geometry.

The wavelength and the maximum growth rate of the fastest-growing waves can be cal culated with analytical correlations as a function of the spray parameters, i.e.:

$$
\begin{gathered}
\frac{\Lambda}{a}=9.02 \frac{\left(1+0.45 \cdot 0 \mathrm{~h}^{0.5}\right)\left(1+0.4 S^{0.7}\right)}{\left(1+0.87 \cdot \mathrm{W} \mathrm{e}_{a}^{1.67}\right)^{0.6}} \\
\Omega\left(\frac{\rho_{p} a^{3}}{\sigma}\right)^{0.5}=\frac{\left(0.34+0.38 \cdot \mathrm{W} \mathrm{e} \mathrm{e}_{a}^{1.5}\right)}{(1+0 \mathrm{~h})\left(1+1.4 S^{0.6}\right)}
\end{gathered}
$$

where $S=0 \mathrm{~h} \cdot(\mathrm{W} \mathrm{e}))^{0.5}$.

H owever, different rates of penetration are observed within and beyond the breakup length because of the presence of an intact core close to the nozzle [24]. To account for this behavior, a model including both $\mathrm{K}$ elvin- $\mathrm{H}$ elmholtz $(\mathrm{K}-\mathrm{H})$ and $\mathrm{R}$ ayleigh-Taylor ( $\mathrm{R}$ $\mathrm{T}$ ) instability criteria has been proposed by R eitz [25]. A ccording to this model, breakup is 
due to $\mathrm{K}-\mathrm{H}$ instability until the spray reaches the breakup length and then breakup occurs due to both $\mathrm{K}-\mathrm{H}$ and $\mathrm{R}-\mathrm{T}$ mechanisms. The value of the breakup length, $L_{b}$, is given by

$$
L_{b}=2 C \cdot r \sqrt{\frac{\rho_{l}}{\rho_{g}}}
$$

where $C$ is an adjustable parameter that depends on the nozzle characteristics. Senecal [26] suggests that the value of the constant $C$, in the limit of high Weber numbers, is equal to $B_{1} / 2$. This is because in the hypothesis of negligible liquid viscosity and gas phase, $\mathrm{W}$ eber number approaches infinity, and the breakup time in the $\mathrm{K}-\mathrm{H}$ model $\left(\tau=3.726 B_{1} a / \Lambda \Omega\right)$ can be reduced to

$$
\tau=\frac{B_{1} r}{|\mathbf{v}-\mathbf{u}|} \sqrt{\frac{\rho_{l}}{\rho_{a}}}
$$

Thus, the breakup length, which is assumed to be $L_{b}=\tau u$, can be calculated as

$$
L_{b}=|\mathbf{v}-\mathbf{u}| B_{1} r \sqrt{\frac{\rho_{l}}{\rho_{a}}}
$$

By comparing Eq. (35) and Eq. (33), it is possible to obtain for the constant $C$ the value of $B_{1} / 2$.

$\mathrm{N}$ eglecting liquid viscosity and considering surface tension only, the analytical fastest- growing frequency, $\Omega_{t}$, and the corresponding wave number, $\mathrm{K}$, predicted by the R-T instability criteria are given by [25]

$$
\begin{gathered}
\Omega_{t}=\sqrt{\frac{2}{3 \sqrt{3 \sigma}} \frac{\left[g_{t}\left(\rho_{l}-\rho_{g}\right)\right]^{3 / 2}}{\rho_{l}+\rho_{g}}} \\
\mathrm{~K}=\sqrt{\frac{-g_{t}\left(\rho_{l}-\rho_{g}\right)}{3 \sigma}}
\end{gathered}
$$

where $g_{t}$ is the acceleration in the direction of travel.

\section{Other Models}

The modified RNG $\kappa-\varepsilon$ turbulence model proposed by $\mathrm{H}$ an and Reitz [27] has been adopted in the present investigation. This model differs from the standard R N G $\kappa-\varepsilon$ 
model through the presence of an extra term in the dissipation equation that accounts for the compressibility of the flow. The modified RN G $\kappa-\varepsilon$ model [27] reproduces the largescale flame structures in a more realistic way, improving the prediction of the high-temperature domains and of $\mathrm{NO}$ and soot emissions. The multi-step Shell ignition model [29] was used together with the laminar and turbulent characteristic-time combustion model [29] to describe the entire combustion process. A temperature threshold of $1100 \mathrm{~K}$ for switching from ignition chemistry $(T<1100 \mathrm{~K})$ to combustion chemistry $(T>1100 \mathrm{~K})$ was chosen. The soot emission models adopted in this study are the $\mathrm{H}$ iroyasu formation model [30] and the $\mathrm{N}$ agle and Strickland- $\mathrm{C}$ onstable oxidation model [31].

\section{COMPARISON BETWEEN EXPERIMENTAL AND NUMERICAL DATA}

Experimental investigation are often performed by using a constant-volume vessel filled with inert gases. The reasons for this choice are manifold. The air motion in the chamber of a diesel engine affects spray-gas interactions and increases uncertainties on spray calculations. $\mathrm{M}$ oreover, the values of temperature and pressure in an engine cylinder are not uniform, and show significant cycle-to-cycle variation. Finally, inert gases prevent combustion in the chamber and allow the study to be performed in high-density environments without combustion. Thus, a constant-volume chamber was first considered to test the effect of variable fuel density on the KIVA $3 V$ results.

For the simulations at constant volume, a cylindrical sector has been used with a number of divisions along the $x, y$, and $z$ axes equal to 30,36 , and 15 , respectively. The spray was simulated to be injected $1.5 \mathrm{~mm}$ from the axis of a cylinder of $120 \mathrm{~mm}$ diameter. The cylinder diameter was sufficient to avoid impingement on the wall.

Initially the effect of grid resolution was investigated by increasing the number of divisions along the $x, y$, and $z$ axes up to 60,36 , and 30 , respectively. $\mathrm{N} o$ significant differences between the two sets of results were observed.

The provisional capability of both standard and modified models has been checked by using experimental data of penetration and Sauter mean radius (SM R) distribution acquired in a previous investigation [32]. T hese measurements refer to sprays injected by a high-pressure common-rail injection system into a vessel at ambient pressure and temperature. Since vaporization is negligible under these operating conditions, this case will be henceforth referred to as nonevaporating spray. All the investigated operating conditions are reported in Table 2.

Table 2 O perating $\mathrm{C}$ onditions for $\mathrm{N}$ onevaporating Sprays

\begin{tabular}{lcccc}
\hline & U nits & C ase A & C ase B & C ase C \\
\hline E nergizing time & $\mu \mathrm{s}$ & 320 & 650 & 1012 \\
N eedle opening time & $\mu \mathrm{s}$ & 590 & 956 & 1362 \\
Injected quantity & $\mathrm{mm}^{3}$ & 16.4 & 28.6 & 50.2 \\
Total fuel mass & $\mathrm{mg}$ & 13.6 & 23.7 & 41.6 \\
A mbient pressure & $\mathrm{M} \mathrm{Pa}$ & 0.1 & 0.1 & 0.1 \\
A mbient temperature & $\mathrm{K}$ & 288 & 288 & 288 \\
Injection pressure & $\mathrm{M} \mathrm{Pa}$ & 90 & 90 & 90 \\
Injection temperature & $\mathrm{K}$ & 313 & 313 & 313 \\
\hline
\end{tabular}


In the present article, unless otherwise specified, comparisons between experimental and numerical data are described only for case $A$, since the comparison for cases $B$ and $C$ leads to very similar results.

The aim of the experimental investigation [32] was to show the different behavior of the five injector holes. Ficarella et al. [32] carried out a photographic characterization of tip penetration and spray angle for each nozzle hole as well as a complete characterization of the droplet size distribution, by means of $M$ alvern technique. The acquisition time for $M$ alvern investigation was set to $100 \mu s$ before the end of the injection, and the laser beam diameter was $9 \mathrm{~mm}$. M easurements were performed at two axial distances ( 24 and $48 \mathrm{~mm}$ ) from the injector hole and at 2-mm-step radial positions from the spray axis. $M$ ore information about the experimental setup and results can be found in [32].

In the present investigation, the correspondence between experimental and numerical measurement positions was obtained by using as control volumes hexahedrons $9 \mathrm{~mm}$ on a side at steps of $4 \mathrm{~mm}$ along the radial direction. The Sauter mean radius in each position was calculated as

$$
\mathrm{SMR}=\frac{\sum N_{p} r_{p}^{3}}{\sum N_{p} r_{p}^{2}}
$$

where the summation is over all parcels in the control volumes, at $100 \mu \mathrm{s}$ before the end of the injection.

Figure 1 shows a comparison between the computed and experimental images of the spray as well as the axial distance at which the SM R was measured.

Figure $2 a$ compares the numerical tip penetration with the experimental data. Since the environment pressure is constant and the droplet temperature changes are very small, differences between the constant-density and variable-density models are small. The value of density versus time predicted by both the tested models was roughly constant and equal to $\rho_{p}(T, p)=819 \mathrm{~kg} / \mathrm{m}^{3}$ and $\rho_{p}\left(T, p, \chi_{a}\right)=777 \mathrm{~kg} / \mathrm{m}^{3}$, respectively. In the case of quiescent air and constant drop radius, drop deceleration is given by

$$
\frac{d \mathbf{v}}{d t}=\frac{9 \mu}{2 p_{l} r^{2}}(\mathbf{u}-\mathbf{v})
$$

Thus, tip penetration increases as fuel density increases. This is confirmed by the results in Fig. $2 a$.

$D$ rop size distribution has been studied by many researchers, who demonstrated the influence of atomization, collision, and drag resistance on the SM R characteristics of dense sprays [24]. T he granulometric characteristics of dense sprays are the results of competition between breakup, which tends to reduce droplets size, and collision, which acts in the opposite direction. Thus, droplet size distribution in the axial and radial directions of sprays depends on the specific operating conditions under which the measurements are carried out, and they can be quite different. Payry et al. [34] and Coghe et al. [35], while investigating diesel sprays injected in a high-density environment, found that the SM R is 

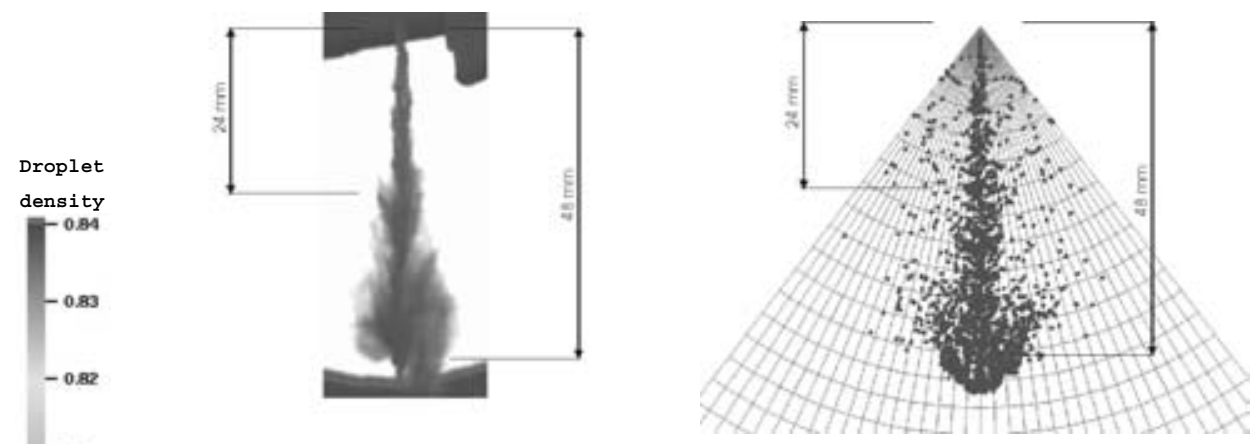

-0.91
-0.8
-0.78
-0.78
-0.77
-0.78

a) experimental image

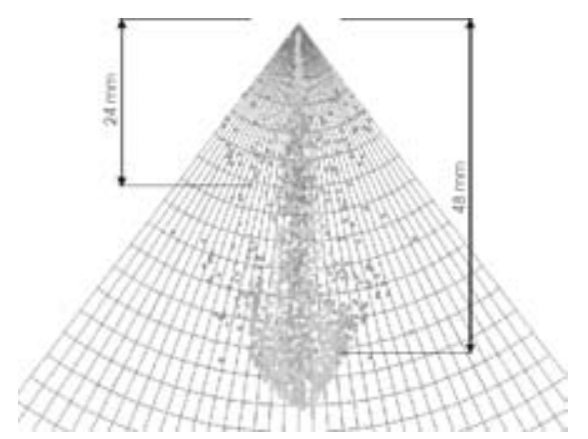

b) $\rho_{p}=$ const

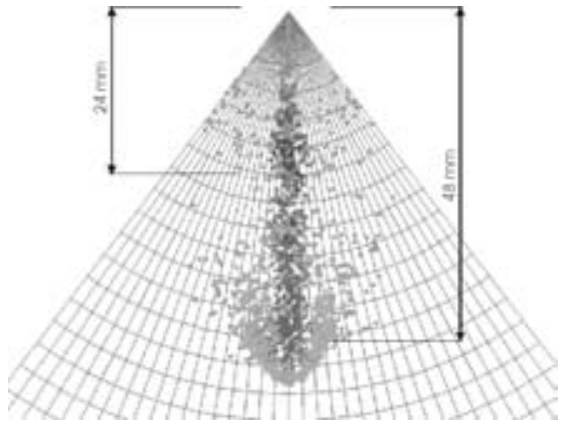

c) $\rho_{p}=f(T, p)$

d) $\rho_{p}=f\left(T, p, \chi_{a}\right)$

Fig. 1 Comparison between experimental and numerical spray images at $100 \mu$ s before end of injection.

approximately constant along the radial direction. $\mathrm{O}$ the other hand, in the case of turbulent dispersion of fuel droplets in an unsteady spray, Kosaka et al. [36] found a drop size distribution with larger diameters in the spray periphery than in the center region of the spray. They justified such behavior by assuming that large droplets, due to their higher mass, are more easily centrifuged to the periphery by the motion of large head vortices in the spray tip. A ccording to this hypothesis, centrifugal forces play an important role in the determination of axial and radial SM R distributions.

Figures $2 b$ and $2 c$ show a comparison between numerical and experimental drop size distributions. Experimental data are ensemble averaged over 20 injections. $D$ ue to the asymmetric behavior of $\mathrm{V}$ alve $\mathrm{C}$ overed $\mathrm{O}$ rifice ( $\mathrm{VCO}$ ) nozzles, each nozzle hole generates a differently shaped spray; thus, an uncertainty bar is plotted in Figs. $2 b$ and $2 c$ to represent the maximum difference between the lowest and the highest values of SM R for the five holes. A Ithough drop average size is the same for both numerical and experimental data, KIVA 3V predicts larger drop diameters in the inner region of the spray at $100 \mu \mathrm{s}$ before the end of injection.

The tendency of KIVA $3 \mathrm{~V}$ is to produce a radial distribution with higher values of SM $R$ along the axis in the case of dense spray due to the high collision probability near the core of the spray. At a 24-mm axial position, droplets with highly unequal radii exist because of the presence of both an intact liquid core and drops generated by the breakup 


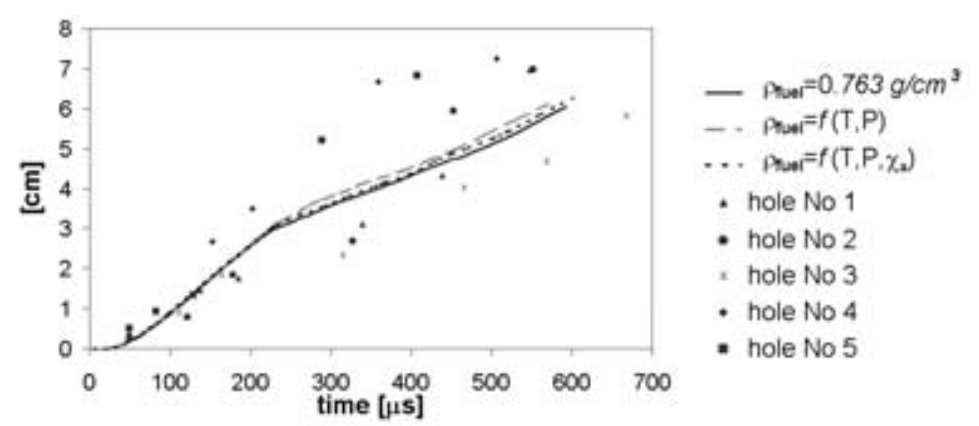

a) Tip penetration versus time.

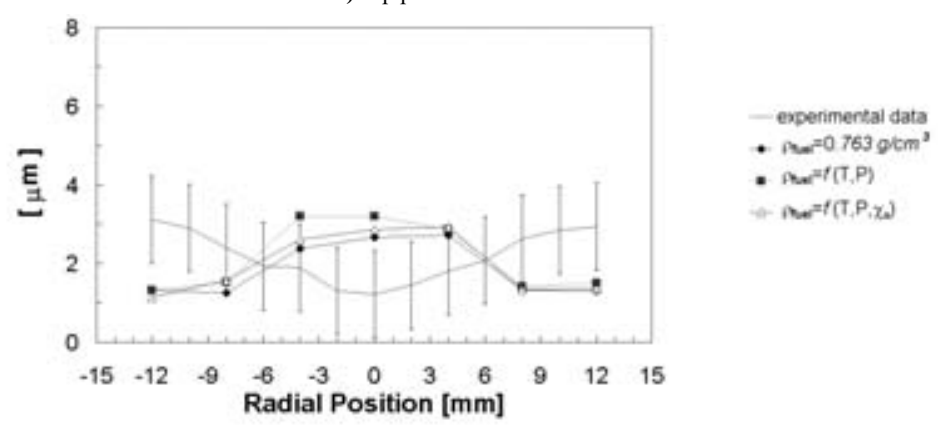

b) SMR radial distribution at a $24 \mathrm{~mm}$ axial position

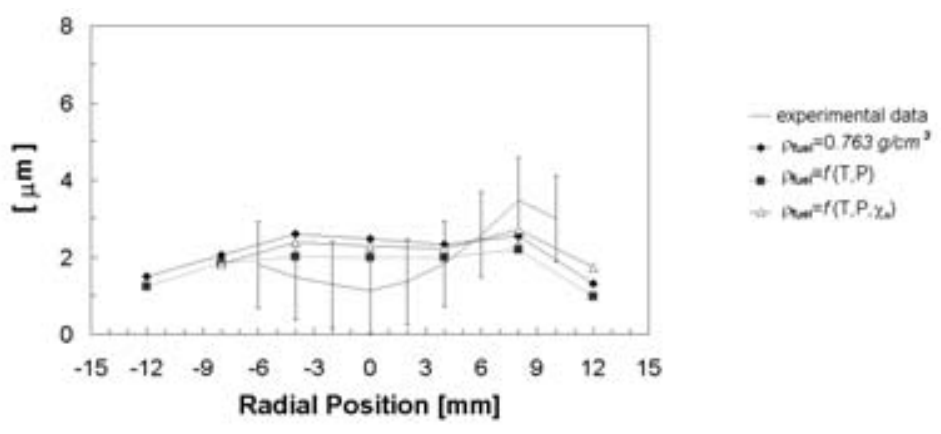

c) SMR radial distribution at a $48 \mathrm{~mm}$ axial position.

Fig. 2 Comparison between experimental and numerical data for case A.

process. The probability of coalescence depends on the ratio of the droplet radii, and $\mathrm{Eq}$. (12) shows that drops of unequal size are more likely to coalesce than drops of nearly equal size. Thus, higher values of drop diameter are predicted in this region.

Figure 3 shows, for the three tested fuel density models, the axial SM R distribution versus time at $48 \mathrm{~mm}$ downstream of the injector nozzle. D uring most of the injection event and for all the investigated cases, the SM R is greater in the inner region of the spray than in the periphery. A s the injection approaches the end (time $=0.0$ ), the SM R calculated at the center of the spray diminishes as the droplet size at the periphery increases. This is caused by the lower energy of the incoming spray at the end of the injection event. By com- 

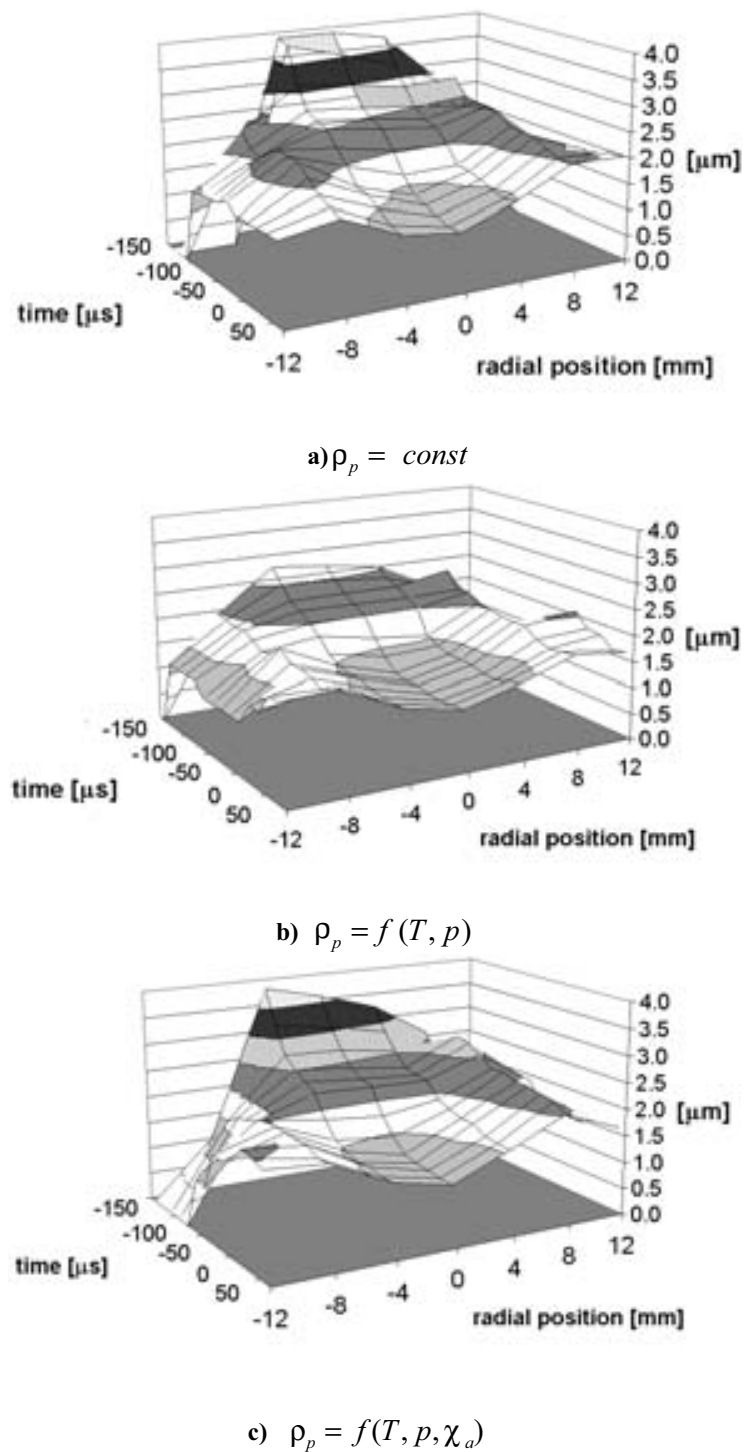

Fig. 3 SM R radial distribution versus time ( $t=0$ at the end of injection).

paring the graphs in Fig. 3, it is possible to observe the effect of fuel density on spray SM R. $N$ ote that in the case of higher average densities, $\rho_{p}(T, p)=819 \mathrm{~kg} / \mathrm{m}^{3}$, the predicted SM R is smaller than in the other cases. Experimental results for nonevaporating spray confirm that the breakup mechanism and the droplets-air interaction are dependent on the gas-toliquid density ratio [3]. In particular, an increase in this ratio leads to larger droplet sizes. Computational fluid dynamics (CFD) calculations carried out by the authors have also shown that by increasing the gas-to-liquid density ratio, a reduction of the average droplet velocity, and therefore a decrease of the collisional Weber number, were observed. This 
Table 3 O perating C onditions for Single-Parcel Investigation

\begin{tabular}{ll}
\hline Pressure & $1 \mathrm{Bar}$ \\
D rop temperature & $313 \mathrm{~K}$ \\
Total injected mass & $3.5 \mu \mathrm{g}$ \\
D rop velocity & $14 \mathrm{~m} / \mathrm{s}$ \\
D rop radius & $10 \mu \mathrm{m}$ \\
\hline
\end{tabular}

means that the aerodynamic force decreases compared to the droplet surface tension, and the probability of breakup decreases, which in turn leads to larger droplets.

\section{EVAPORATING SPRAYS}

Fuel density variability was expected to have a larger influence on evaporating sprays because of the larger temperature gradients. The modified vaporization model [E q. (25)] allows the increase of drop radius, due to a reduction in fuel density, to be predicted during the heatingup period. Therefore, a correct volume/surface ratio for each parcel can be determined.

To understand the effect of the variable-density models, the injection of a single parcel was simulated in a high-temperature environment. In this way, the effects of breakup and collision on the vaporization rate were eliminated. Three temperature values $(400,600$, and $800 \mathrm{~K})$ for the chamber were analyzed, and the conditions listed in Table 3 were chosen.

Figure 4 shows parcel density and vaporized mass for the three temperature values using the two density models and the constant value of $820 \mathrm{~kg} / \mathrm{m}^{3}$ (corresponding to gasoil density at the injection conditions: $313 \mathrm{~K}, 50 \mathrm{bar}$ ).

If fuel density is allowed to change, a density decrease versus time in both cases, $\rho_{p}=f(T, p)$ and $\rho_{p}=f\left(T, p, \chi_{a}\right)$, can be noticed, and this is due mainly to the heating of the drops. $M$ oreover, the presence of air in the fuel produces an additional decrease in density that results in an increased vaporization rate.

Two effects must be considered to understand the correlation between drop density and vaporization rate: the increase in heat exchange due to the drop surface increasing, and the influence of droplets mass on the heating rate. The key factor in the study of a single-parcel case is the injection model used by KIVA 3V. From E qs. (28) and (27), it is possible to notice that for a given injected mass, the parcel created by the "blobs injection model" contains a number of droplets inversely proportional to the initial liquid fuel density and radius equal to the nozzle radius. U nder the same conditions, droplets with lower density have lower mass; therefore they are prone to a faster vaporization. Figure 5 shows the effect of the heating-up period on drop size when fuel density variability is considered, and the results are compared with the constant-density case.

In the case of low ambient temperature $(400 \mathrm{~K})$, the droplet expansion is reduced compared with the others; thus, the effect of the increased heat exchange caused by the drop surface increasing can be neglected and the vaporization rate depends mainly on the droplet mass, i.e., on the initial value of their density. In this case the parcel is formed by a nearly equal number of droplets for both cases at $\rho_{p}=f(T, p)$ and $\rho_{p}=$ const since the initial density is nearly the same, as shown in Fig.4a.T hus,the droplets generated in the two 

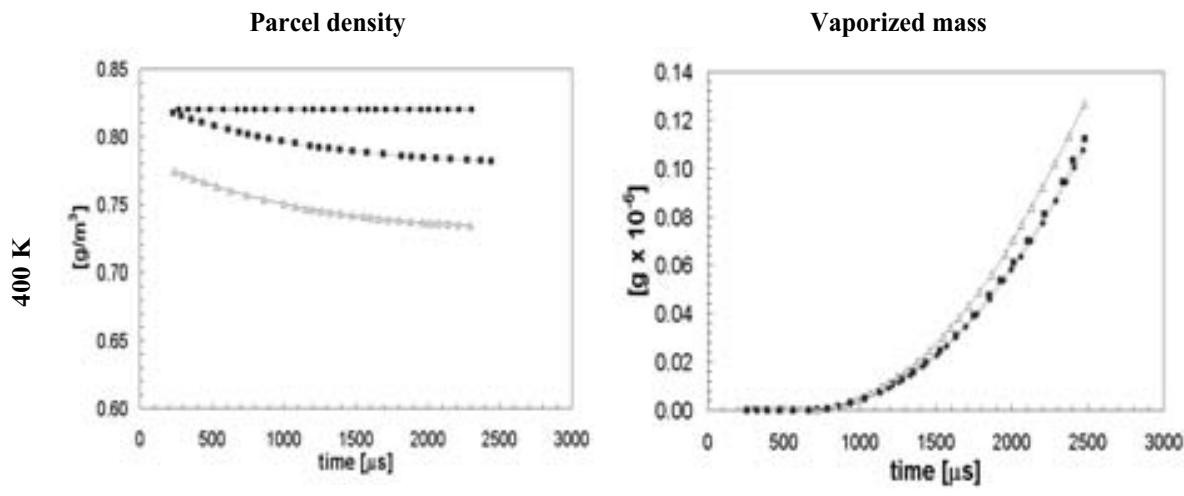

b)
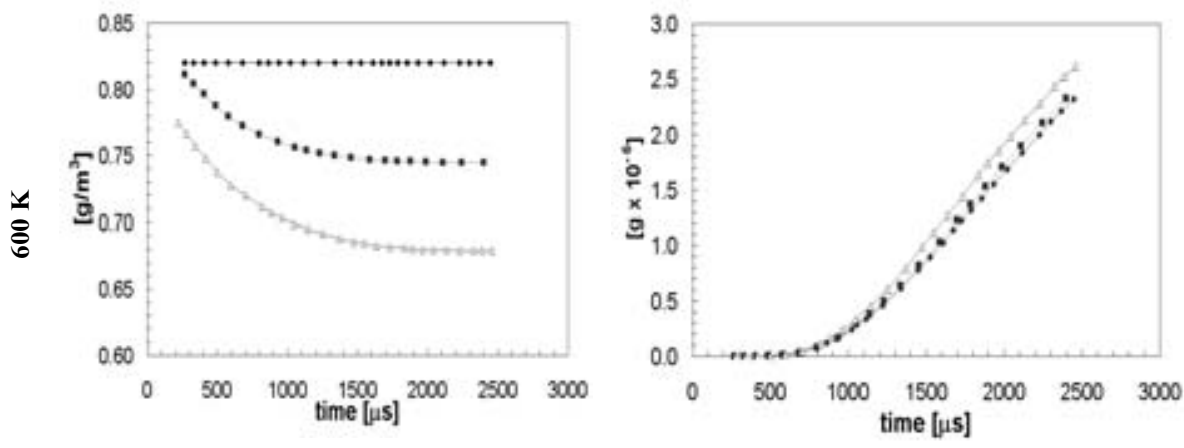

c)

d)
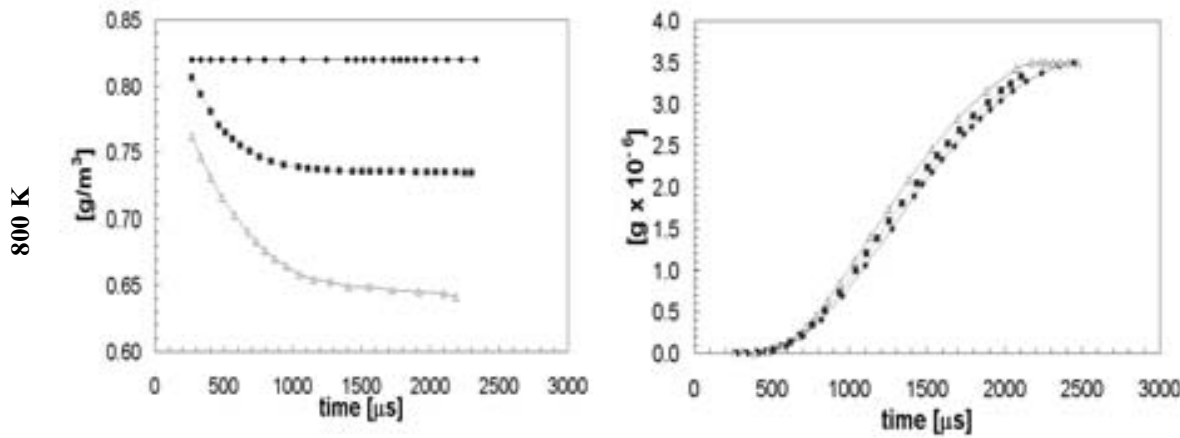

f)

e)

$$
\leftarrow \rho_{p}=0.82 \mathrm{~g} / \mathrm{cm}^{3}-\rho_{p}=f(T, p) \longleftarrow \rho_{p}=f\left(T, p, \chi_{a}\right)
$$

Fig. 4 D roplet density and vaporized mass for the single-parcel case.

cases have about the same mass. W hen drop density is calculated as $\rho_{p}=f\left(T, p, \chi_{a}\right)$, the initial value of density is much less than $820 \mathrm{~kg} / \mathrm{m}^{3}$, so a higher number of drops with lower mass than in the other two cases is obtained, and the resulting heating rate is higher.

As ambient temperature increases, the two effects (drop surface increasing with temperature and heating rates depending on droplet mass) coexist, and the vaporization rate seems to be proportional to the time-averaged parcel density (Figs. $4 c-f$ ). 

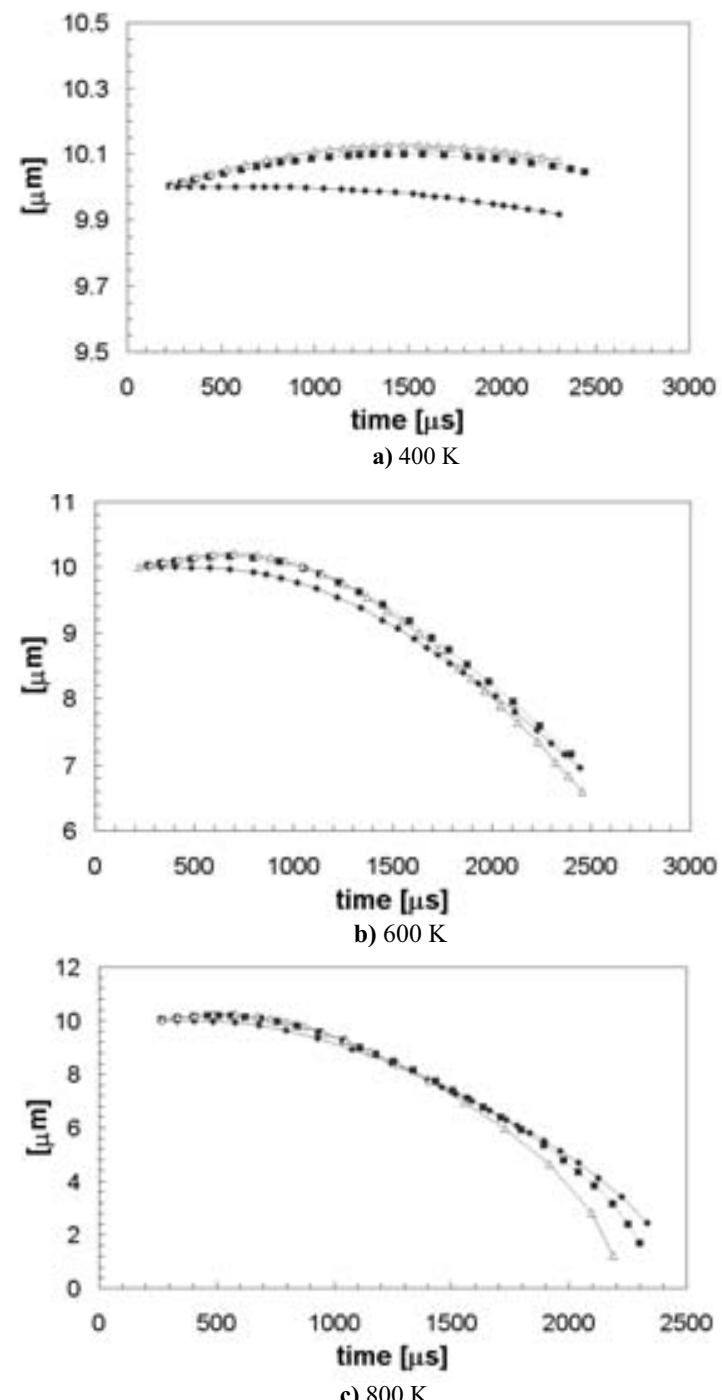

Fig. 5 D roplet radius versus time for the single-parcel case.

Further considerations are needed to explain the drop radius trends versus time reported in Fig. 5. A t the beginning, an increasing drop diameter can be predicted by $\mathrm{E}$ q. (25), due to the heat exchange with the surrounding air. This effect is not present in the constant-density case since the temperature increase has no influence on fuel density. $0 \mathrm{n}$ the other hand, droplet size decreases due to vaporization; when this effect prevails, the drop radius diminishes and the rate of decrease depends on the vaporization rate.

By examining Fig. $5 c$ for $800 \mathrm{~K}$ ambient temperature, it is possible to notice that a longer droplet lifetime is predicted under the hypothesis of constant density than in the cases of variable density. Similar results were also found by $\mathrm{G}$ onzales et al. [7]. 
A lthough the increase of droplet radius versus time could be considered negligible, it must be taken into account when fuel density is allowed to change. This statement can be proved with the use of a reductio ab absurdum, by considering the algorithm used by KIVA $3 \mathrm{~V}$ to calculate the parcel vaporization rate. In the case of nonconstant density, the mass vaporized from a single parcel is calculated in the vaporization subroutine with the following difference:

$$
\Delta m_{p}=N_{p}^{\prime \prime} \frac{4}{3} \pi\left[\left(r_{p}^{A}\right)^{3} \rho_{p}^{A}-\left(r_{p}^{\prime \prime}\right)^{3} \rho_{p}^{\prime \prime}\right]
$$

The following hypotheses will be considered for the proof:

1. The droplets of the parcel undergo a process of heating up without vaporizing during the time step.

2. Parcel density depends on droplet temperature and pressure.

3. The drop expansion is not taken into account (i.e., droplet size is independent of density).

4. The number of droplets in the parcel does not change.

$D$ ue to the heat exchange between the parcel and the surrounding air, droplet temperature increases. Thus, the parcel density $\rho_{p}$ decreases between phase $A$ and phase " of the calculation $\left(\rho_{p}^{A}<\rho_{p}^{\prime \prime}\right) O \mathrm{n}$ the other hand, the droplet radius keeps the same value $\left(r_{p}^{A}=r_{p}^{\prime \prime}\right)$. A s a result of these effects, E q. (40) predicts a quantity $\Delta m_{p}$ of vaporized parcel mass, which contrasts with the hypothesis of nonevaporating droplets. Thus, the importance of calculating the effects of heat exchange on drop radius rate by Eq. (25) instead of Eq. (26) is proven.

The temperature law of variation during the heating-up and vaporization periods is the same [E q. (20)] in both cases of constant and variable density. H owever, the rate of temperature increase is underestimated when drop radius variation with density is not taken into account, as the heat exchange between the liquid phase and the surrounding air is proportional to drop surface.

After this preliminary study on a single parcel, the same operating conditions of the nonevaporating case (see Table 2 ) were considered to investigate three cases of evaporating sprays with environment temperatures of 400,600 , and $800 \mathrm{~K}$ and a pressure of 12 bar, respectively.

Figure 6 shows that the effect of the air dissolved in the fuel on the average drop density is quite small in the case of 12 bar. Simulations carried out for an ambient pressure higher than 20 bar have shown virtually no differences due to the presence of air dissolved in the fuel.

By comparing the results of Fig. 6 for the three values of temperature, it can be noticed that the trends of vaporized mass versus time are different from those observed in the single-parcel case when the air dissolved in the fuel is taken into account. In particular, even though the average fuel density calculated as $\rho_{p}=f\left(T, p, \chi_{a}\right)$ is lower than the other cases, the vaporization rate at 400 and $600 \mathrm{~K}$ follows a contradictory trend. This phenomenon was not observed in the case of the single parcel (see Fig. 4), and it could be explained as follows. W hen sprays are considered, many mechanisms, such as collision and breakup, affect droplet vaporization. M oreover, very small drops heat up and vaporize ear- 

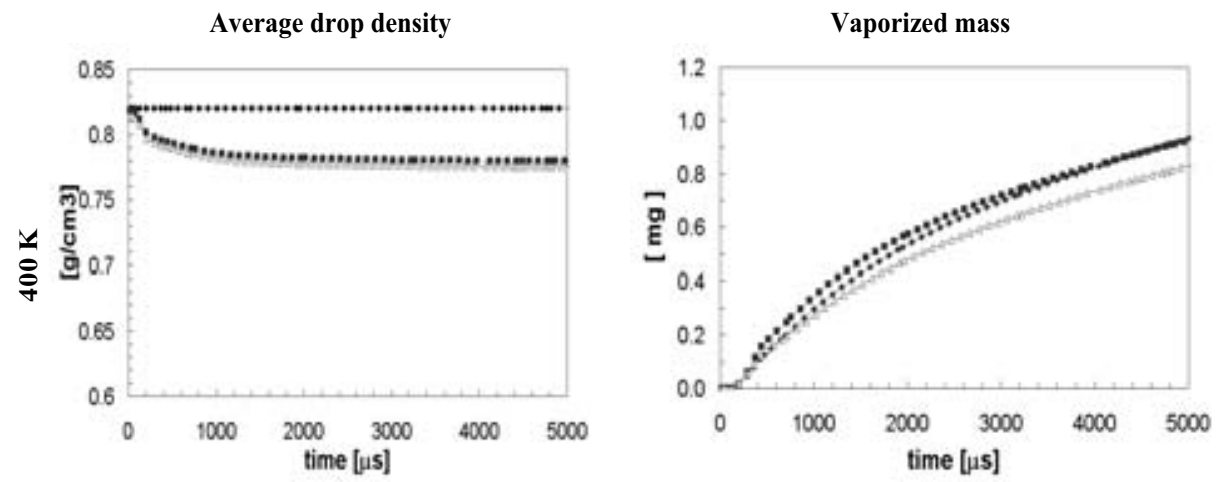

a)

b)
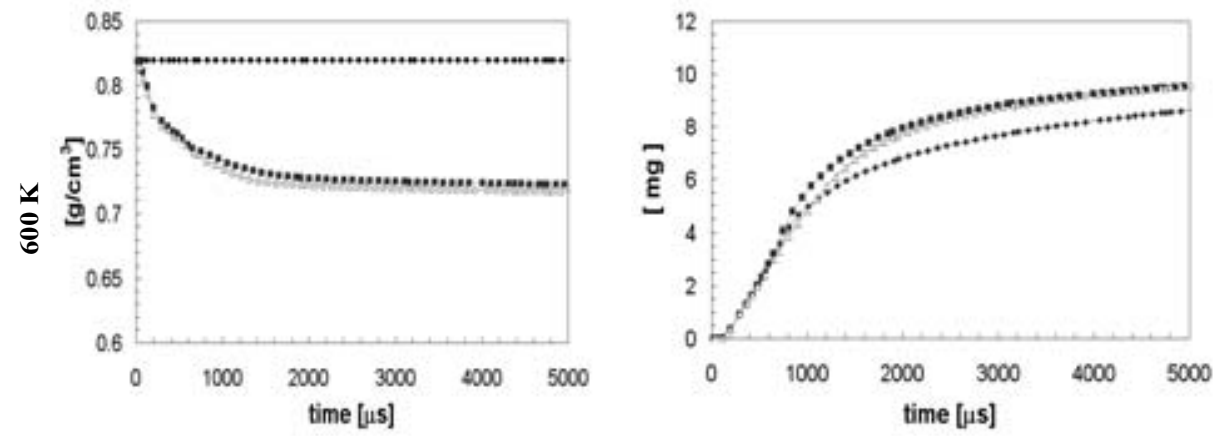

c)

d)
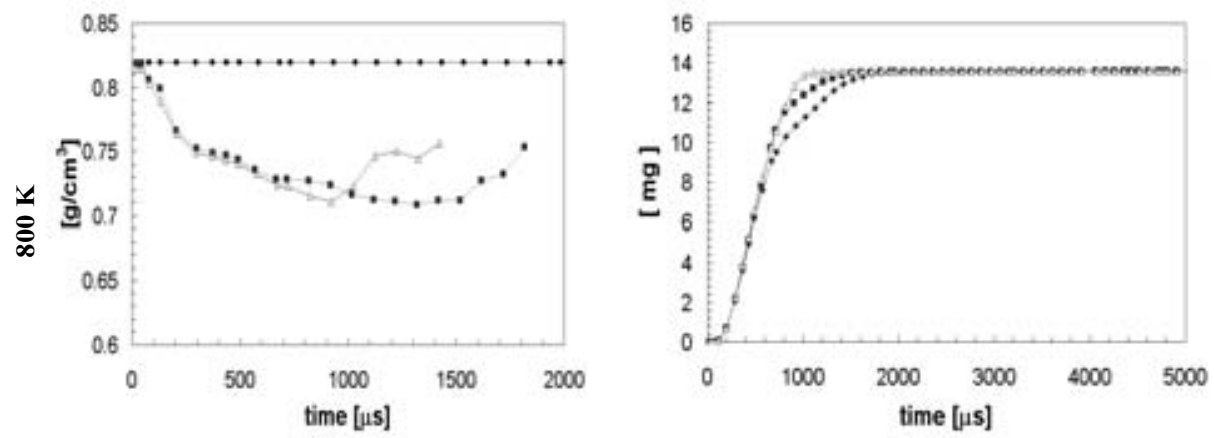

e)

f)

$$
\bullet \rho_{p}=0.82 \mathrm{~g} \mathrm{~cm}^{3} \bullet \rho_{p}=f(T, p) \multimap \rho_{p}=f\left(T, p, \chi_{a}\right)
$$

Fig. 6 A verage drop density and vaporized mass for the spray case.

earlier, thus the average size of drops increases due to the dynamics of the vaporization process. A ccording to the atomization model used for the simulations [25], the radius of the drops produced by the breakup process depends on both liquid and gas density. The probability of collision depends on the characteristics of the colliding drops, especially on their radius and density [E q. (12)]. The combined effects of breakup and collision phenomena have been al ready analyzed in the case of a nonevaporating spray. In the same 

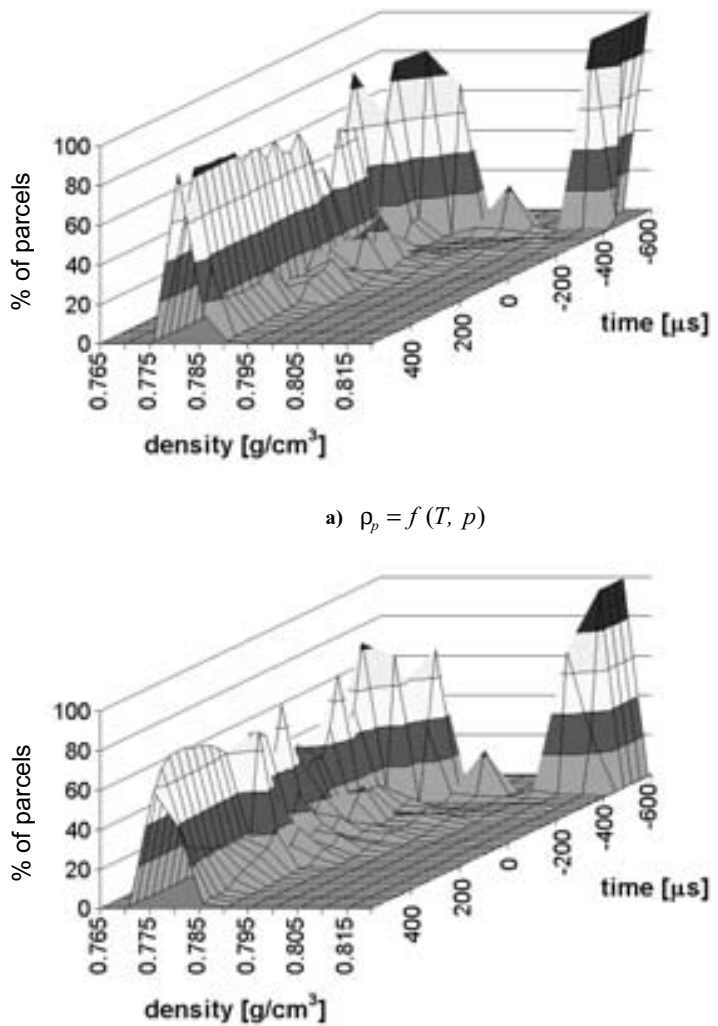

b) $\rho_{p}=f\left(T, p, \chi_{a}\right)$

Fig. 7 D roplet density distribution versus time at $400 \mathrm{~K}$ environment temperature ( $t=0$ at the end of injection).

way it is possible to state that the interaction among the processes involved in spray evolution produces manifold results which are hard to quantify.

In Fig. 7 the droplet density distribution versus time is shown for the two variabledensity models. $N$ ote that a different drop density distribution is predicted when the presence of air dissolved in the fuel is taken into account, even if the average drop density is roughly the same for the two variable-density models at 12 bar. This can be explained by noting that the density variability effect is mitigated by the droplet-droplet interactions. Thus, the overall droplet characteristics are only weakly influenced, as shown in Fig. 8.

Finally, it is possible to state that drop radius distribution is not strongly affected by the density model because of the combined influence of the several phenomena, as shown in Fig. 9.

\section{COMPARISON OF ENGINE EXPERIMENTAL AND NUMERICAL DATA}

CFD codes are often used to explore injection strategies for engine pollutant emission control. Thus, the assessment of the provisional capability of these codes is a very important 

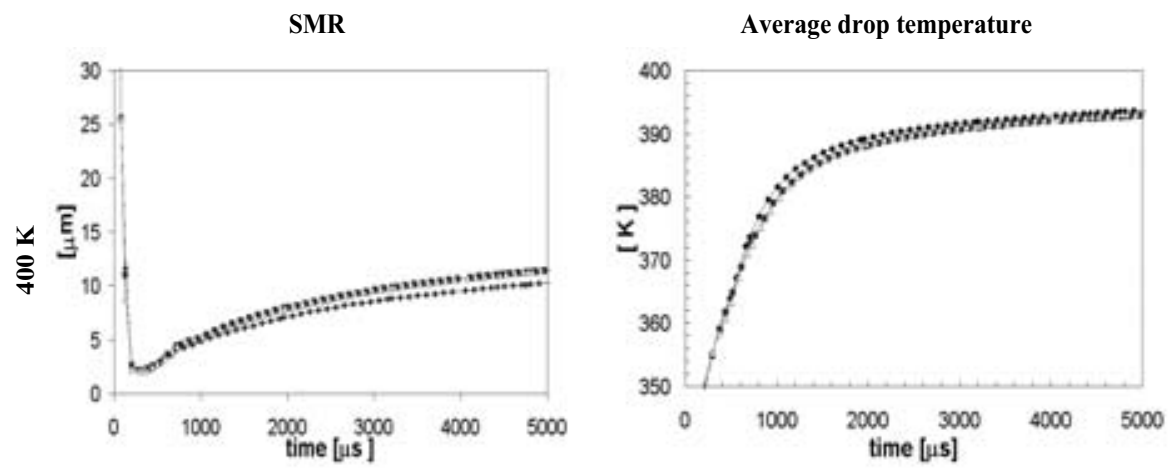

a)

b)
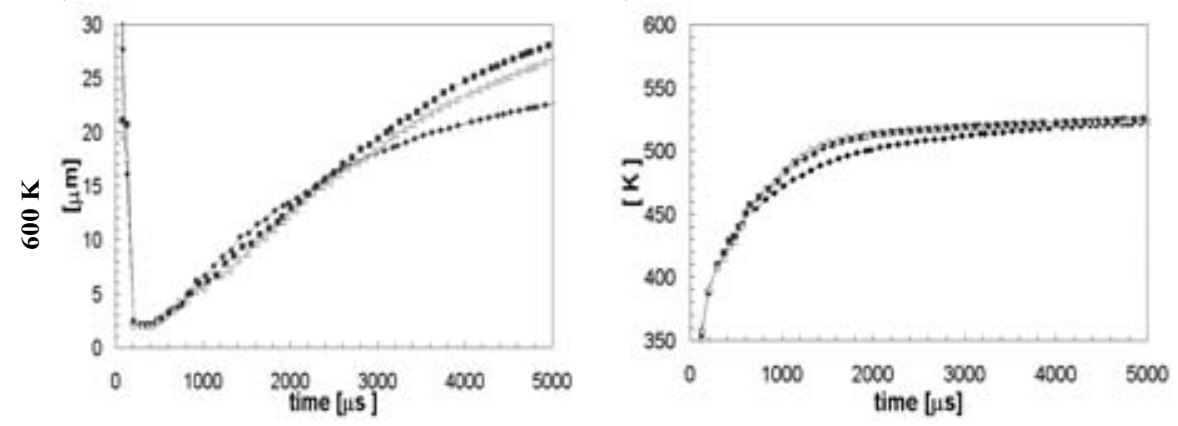

c)

d)
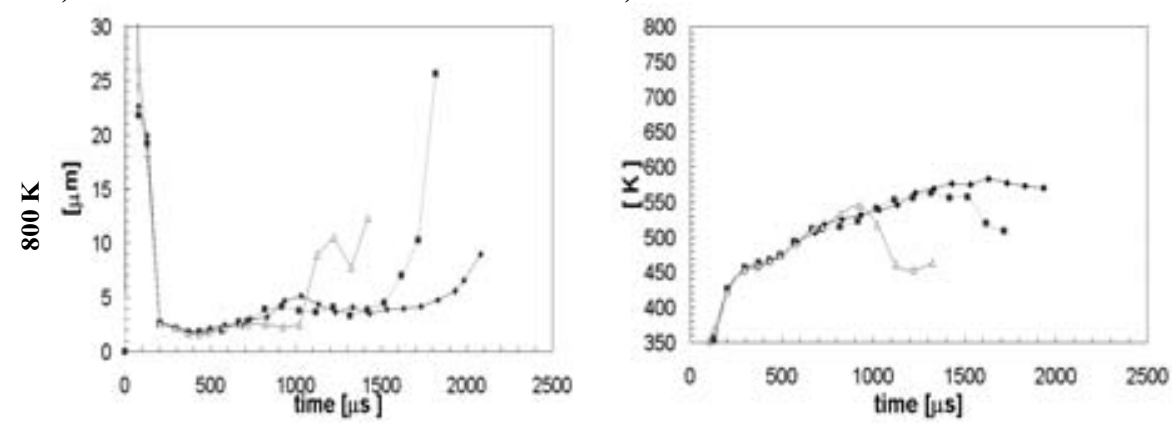

f)

$\rightarrow \rho_{p}=0.82 \mathrm{~g} / \mathrm{cm}^{3}-\rho_{p}=f(T, p) \multimap \rho_{p}=f\left(T, p, \chi_{a}\right)$

Fig. 8 SM R and average drop temperature for the spray case.

issue in the case of engine simulations. O nce again, the standard KIVA $3 \mathrm{~V}$ and the modified version presented in the present investigation were used to compare the calculated and measured emission levels of a direct-injection diesel engine equipped with a common-rail injection system.

The experimental data were acquired by using a commercial small-bore, high-speed engine, provided with adequate instrumentation for the control of the operating conditions and for the measurement of emissions and performance parameters. The engine specifications are summarized in Table 4. 


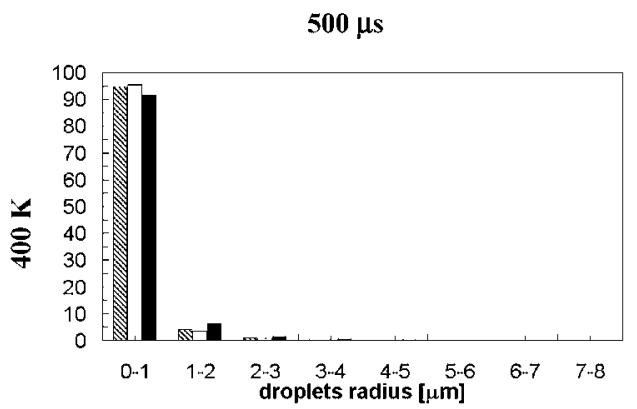

a)

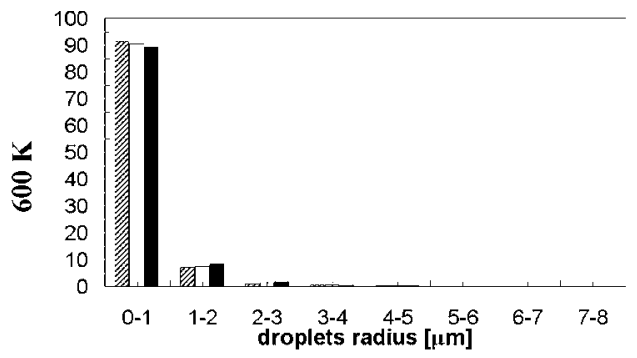

b)

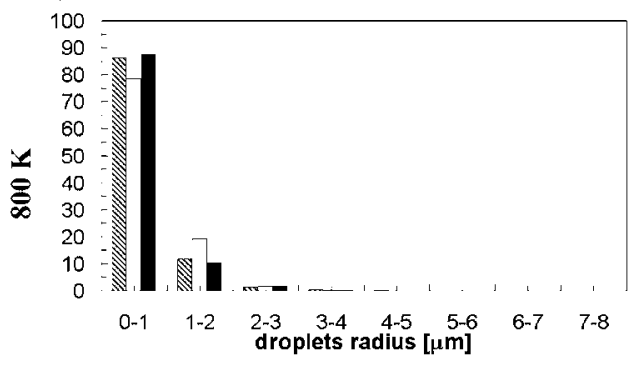

c)

$$
\Delta \rho_{p}=0.82 \mathrm{~g} / \mathrm{cm}^{3} \quad \square \rho_{p}=f(T, p) \quad \square \rho_{p}=f\left(T, p, \chi_{a}\right)
$$

Fig. 9 D roplets radius distribution vrsus time for a $400 \mathrm{~K}$ environment temperature.

The injection was performed by using a six-hole VCO nozzle centrally located in an axisymmetric geometry. Thus, to reduce the computational time, a $60^{\circ}$ sector mesh has been used. The mesh was characterized by 20 cells in the radial direction, 20 cells in the longitudinal direction, and 37 cells in the axial direction, with a minimum of 17 cells at top dead center (TDC). The cylinder dome was of conic shape, while the bowl was of reentrant type. The resulting computational grid at T DC is shown in Fig. 10.

The combustion and emissions models used for the simulations have been previously described in the models section. For the breakup model, the values of 25 and 12.5 were chosen for $B_{1}$ and $C$, respectively [E qs. (33)-(35)].

The engine was run at $2800 \mathrm{rev} / \mathrm{min}$ and at $50 \%$ load, and data were acquired at four different values of the start of injection. The investigated operating conditions are summarized in Table 5. 
Table 4 Engine Specifications

\begin{tabular}{ll}
\hline N umber of cylinders & 4 \\
Bore & $88.0 \mathrm{~mm}$ \\
Stroke & $88.4 \mathrm{~mm}$ \\
Connecting rod length & $149 \mathrm{~mm}$ \\
Compression ratio & 19 \\
Intake valves closing (IVC) & $173^{\circ}$ BT DC \\
N umber of nozzles & 6 \\
N ozzle diameter & $169 \mu \mathrm{m}$ \\
Injection system & Common R ail \\
\hline
\end{tabular}

A comparison between experimental and numerical pressure traces for cases 1-4 is shown in Fig. 11. It is interesting to notice the presence of fluctuations in the experimental pressure traces. These fluctuations are believed to be caused by the presence of noise due to pressure wave fluctuation at the position of the sensor in the combustion chamber. In fact, the frequency of the pressure fluctuation in the experimental data ( $16.8 \mathrm{kH} \mathrm{z}$ ) corresponds to a length of about $48 \mathrm{~mm}$, which is about twice the distance between the pressure sensor and the facing wall.

Although the computed compression and expansion pressure traces match the experimental ones, there is a difference of about $11 \%$ between experimental and numerical pressure peaks. T his gap could be reduced by adjusting the parameters of the combustion models that affect the laminar and turbulent characteristic times. $\mathrm{H}$ owever, the standard values of laminar and turbulent times were chosen because predicted $\mathrm{NO}$ and soot levels have been shown to be strongly dependent on the values of these parameters [33].

Comparisons of soot versus $\mathrm{N} O$ trade-offs for the three density models are shown in Fig. 12 as the injection timing was varied over a range of -15 to $-3^{\circ}$ AT D C . For comparison, the experimental values are also reported, and for each datum, the start of the injection is displayed. In spite of the significant differences between experimental and numerical pressure peaks, the code reasonably predicts the ignition delay and the soot- $\mathrm{N} O$ trade- off as the injection timing is varied.

As far as the effect of fuel density variability is concerned, plots of Fig. 11 show there are no noteworthy differences among the results obtained by using the three density models. These results are consistent with the constant-chamber outcomes for evaporating sprays, which revealed that only the local air-droplet and droplet-droplet interactions

Table $5 \quad 0$ perating C onditions for E ngine Simulations

\begin{tabular}{ll}
\hline Total injected mass & $27.8 \mathrm{mg}$ \\
Injection duration & $17.4^{\circ}$ \\
Pressure at IVC & $0.17 \mathrm{M} \mathrm{Pa}$ \\
Temperature at IVC & $325 \mathrm{~K}$ \\
Engine speed & $2800 \mathrm{rpm}$ \\
Start of injection & C ase $1=15^{\circ}$ BT DC \\
& Case $2=11^{\circ}$ BT DC \\
& Case $3=7^{\circ}$ BT DC \\
& Case $4=3^{\circ}$ BT D C \\
\hline
\end{tabular}




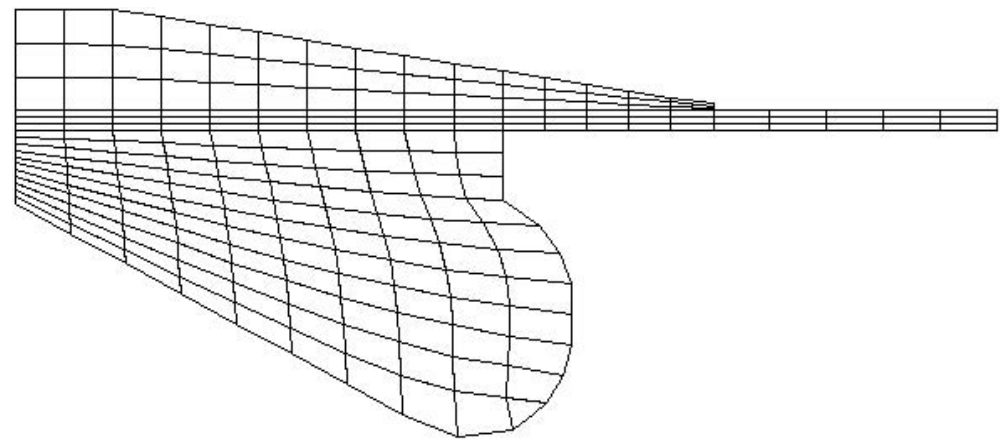

Fig. 10 Engine grid at T DC.

were affected by liquid-phase density distributions, while the combined effects of breakup, collision, and vaporization processes resulted in macroscopic spray characteristics which were weakly influenced by the fuel density variability.

$M$ oreover, the average values of pressure and temperature during the injection event are very high for the analyzed operating conditions. Thus, the vaporization rate is very high and almost independent of the liquid fuel density.
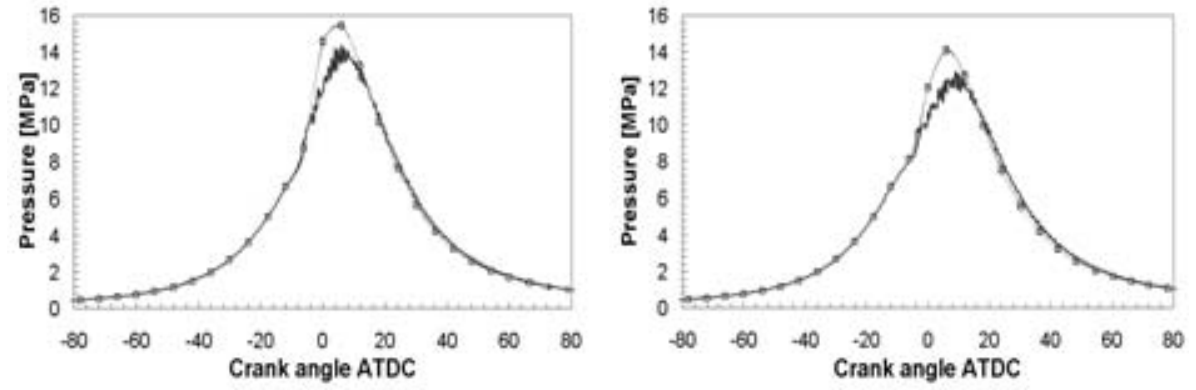

a) CASE 1

b) CASE2
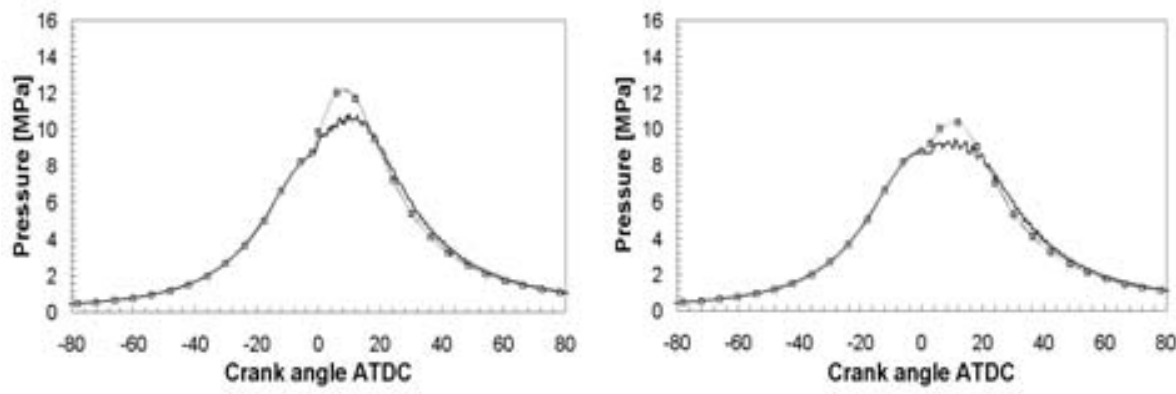

c) CASE 3

d) CASE 4

$$
\text { Experimental data }-\rho_{p}=0.82 \mathrm{~g} / \mathrm{cm}^{3} \rightarrow \rho_{p}=f(T, p) \multimap \rho_{p}=f\left(T, p, \chi_{0}\right)
$$

Fig. $11 M$ easured and predicted engine pressure traces. 


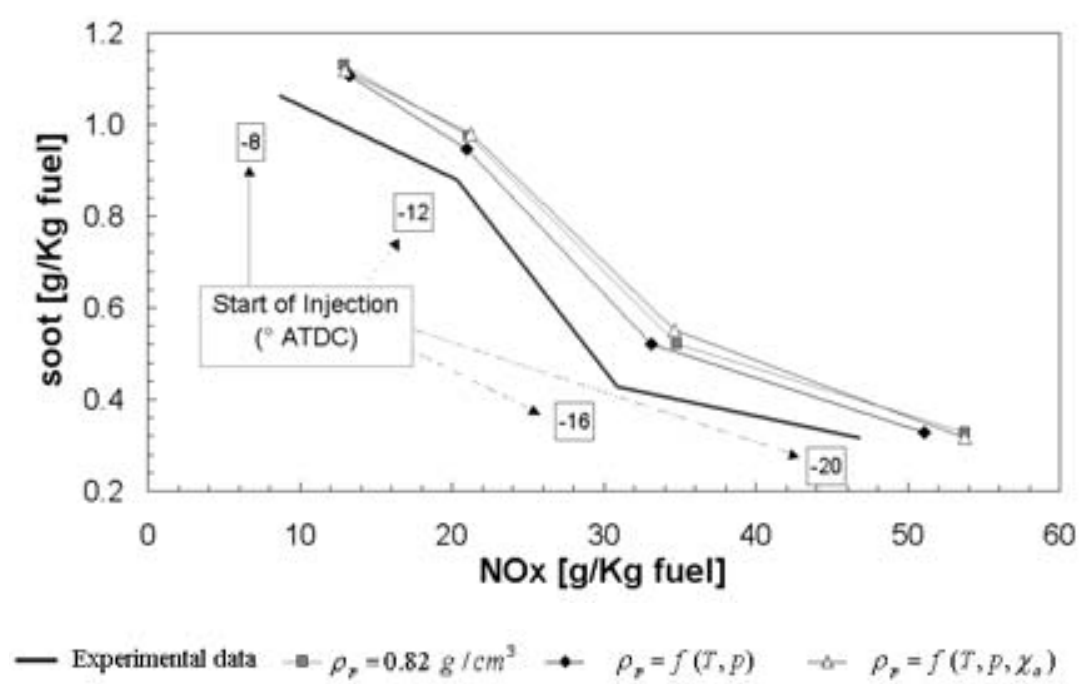

Fig. $12 \mathrm{M}$ easured and predicted $\mathrm{N} \mathrm{O}$-soot trade- off for the engine case.

Since pollutant emissions are controlled by details of the turbulent fuel-air mixing and combustion processes, differences in liquid-phase density distribution affect soot- $\mathrm{N} O$ trade-off. N ote that the influence of variable fuel density is lower when the injection occurs close to TDC, i.e., in the case of very high values of pressure and temperature in the combustion chamber, because of the faster vaporization and combustion. $\mathrm{O} \mathrm{n}$ the other hand, the effect of drop density variability is more significant for early injections because, in these conditions, the vaporization rate tends to be more effective.

Since the functions $\rho_{p}=f(T, P)$ and $\rho_{p}=f\left(T, p, \chi_{a}\right)$ give about the same value of density at pressures higher than 20 bar, the different behavior of the code in the two cases could be explained by considering that the liquid internal energy is influenced by the presence of air dissolved in fuel [E q. (4)], so that droplet thermodynamic properties are different.

\section{SUMMARY AND CONCLUSIONS}

The objective of this study was the implementation of a model for liquid-phase density calculation in the KIVA $3 \mathrm{~V}$ code. The model allows the parcel density to be calculated with a function of droplet temperature and pressure, and the air dissolved in the fuel can also be taken into account. The provisional capability of the modified subroutines was tested by using experimental data for non evaporating sprays injected into a vessel at ambient temperature and pressure. Good agreement was found between experimental and numerical results for both the original and modified codes.

The model prediction of the droplet vaporization rate was studied for different values of temperature for both single-parcel and evaporating sprays. A direct correlation between vaporization rate and parcel density can be found in the case of a single parcel. In the case of evaporating sprays, because of the combined effect of breakup and collision, the 
vaporization process becomes a not univocal function of liquid density. $\mathrm{H}$ owever, a difference of about $10 \%$ in the vaporization rate was observed by using different density models.

$D$ rop size and density distribution were found to be influenced by the model chosen for the fuel density calculation, while the jet macroscopic characteristics are not affected by changes of the liquid density.

Engine investigation confirmed that the overall spray evolution is not affected by fuel density variability. The predicted levels of $\mathrm{NO}$ and soot emissions are influenced by fuel density variability depending on the local vaporization, air-fuel mixing, and combustion phenomena.

\section{APPENDIX: NUMERICAL DIFFERENCING OF THE CONSERVATION EQUATIONS}

Because of fuel density variability, new terms including density contributions arise in all the gas-liquid exchange equations. The conservation equations can be written as follows:

$$
\begin{aligned}
& \frac{d \rho_{i 4}^{s}}{d t}=-\frac{1}{V_{i 4}^{n} \cdot \Delta t} \sum_{p \in i 4} N_{p}^{\prime} \frac{4}{3} \pi\left[\left(r_{p}^{A}\right)^{3} \rho_{p}^{A}-\left(r_{p}^{\prime \prime}\right)^{3} \rho_{p}^{\prime \prime}\right] \\
& \frac{d W_{i 4}^{s}}{d t}=-\frac{1}{V_{i 4}^{n} \cdot \Delta t} \sum_{p \in i 4} N_{p}^{\prime \prime} \frac{4}{3} \pi \rho_{p}^{A}\left(r_{p}^{A}\right)^{3}\left(\mathbf{v}_{p}^{t}-\mathbf{v}_{p}^{\prime \prime}\right) \cdot \mathbf{u}_{p}^{\prime}
\end{aligned}
$$

where the sum is over all parcels in the cell $i 4$ and $\mathbf{v}_{p}^{t}$ is a partially updated particle velocity obtained as described by A msden et al. [17] by solving the particle acceleration equation:

$$
\mathbf{v}_{p}^{t}=\frac{D_{p} \cdot \Delta t}{1+D_{p} \cdot \Delta t} \cdot \mathbf{u}_{i 4 m}^{n}+\frac{\mathbf{v}_{p}^{t}+\mathbf{u}_{p}^{\prime} \cdot D_{p} \cdot \Delta t}{1+D_{p} \cdot \Delta t}
$$

Internal energy exchange rate is calculated according to A msden et al. [17]

$$
\begin{gathered}
\frac{d Q_{i 4}^{s}}{d t}=-\frac{1}{V_{i 4}^{n} \cdot \Delta t} \sum_{p \in i 4} N_{p}^{\prime \prime} \frac{4}{3} \pi\left\{\left(r_{p}^{A}\right)^{3} \rho_{p}^{A} I_{l}\left(T_{p}^{A}\right)-\left(r_{p}^{\prime \prime}\right)^{3} \rho_{p}^{\prime \prime} I_{l}\left(T_{p}^{\prime \prime}\right)\right. \\
+\left(r_{p}^{A}\right)^{3} \rho_{p}^{A}\left(\mathbf{v}_{p}^{t}-\mathbf{v}_{p}^{\prime \prime}\right) \cdot\left(\mathbf{v}_{p}^{t}-\mathbf{u}_{i 4 m}^{n}-\mathbf{u}_{p}^{\prime \prime}\right) \\
\left.+\frac{1}{2}\left[\left(r_{p}^{A}\right)^{3} \rho_{p}^{A}-\left(r_{p}^{\prime \prime}\right)^{3} \rho_{p}^{\prime \prime}\right]\left|\mathbf{v}_{p}^{t}-\mathbf{u}_{i 4 m}^{n}\right|^{2}\right\}
\end{gathered}
$$

Under the hypothesis of variable fuel density, air-spray momentum exchange can be calculated with the following equation: 


$$
\left(M^{\prime \prime}\right)_{i 4}^{B} u_{i 4}^{B}-\left(M^{\prime \prime}\right)_{i 4}^{n} u_{i 4}^{n}=\mathbf{E}_{i 4}-\sum_{p \in i 4} N_{p}^{\prime \prime} \frac{4}{3} \pi\left[\left(r_{p}^{B}\right)^{3} v_{p}^{B} \rho_{p}^{B}-\left(r_{p}^{\prime \prime}\right)^{3} v_{p}^{\prime \prime} \rho_{p}^{\prime \prime}\right]
$$

where $\mathbf{E}_{i 4}$ includes all contributions to the gas momentum, except for the effect of spray-gas interaction.

A fter some manipulations, E q. (A 5) can be written as follows:

$$
\begin{gathered}
\left(M^{\prime \prime}\right)_{i 4}^{B} u_{i 4}^{B}-\left(M^{\prime \prime}\right)_{i 4}^{n} u_{i 4}^{n} \\
=\mathrm{E}_{i 4}-\sum_{p \in i 4} N_{p}^{\prime \prime} \frac{4}{3} \pi \rho_{p}^{B}\left[\left(r_{p}^{B}\right)^{3} v_{p}^{B}-\left(r_{p}^{\prime \prime}\right)^{3} v_{p}^{\prime \prime}\right] \\
+\sum_{p \in i 4} N_{p}^{\prime \prime} \frac{4}{3} \pi \cdot\left(r_{p}^{\prime \prime}\right)^{3} v_{p}^{\prime \prime}\left[\rho_{d}^{B}-\rho_{p}^{\prime \prime}\right]
\end{gathered}
$$

The updated velocity $\mathbf{v}_{p}^{B}$ is obtained by solving the droplet acceleration equation:

$$
\frac{\mathbf{v}_{p}^{B}-\mathbf{v}_{p}^{\prime \prime}}{\Delta t}=D_{p}\left(\mathbf{u}_{i 4}^{B}+\mathbf{u}_{p}^{\prime \prime}-\mathbf{v}_{p}^{B}\right)
$$

Thus, the updated drop velocity is given by:

$$
\mathbf{v}_{p}^{B}=\frac{D_{p} \cdot \Delta t}{1+D_{p} \cdot \Delta t} \mathbf{u}_{i 4}^{B}+\frac{\mathbf{v}_{p}^{\prime \prime}+\mathbf{u}_{p}^{\prime} D_{p} \cdot \Delta t}{1+D_{p} \cdot \Delta t}
$$

where the drag function $D_{p}$ is

$$
D_{p}=\frac{3}{8} \frac{\rho_{i 4}^{n}}{\rho_{f}} \frac{\left|\mathbf{u}_{i 4}^{n}+\mathbf{u}_{p}^{\prime}-\mathbf{v}_{p}^{B}\right|}{r_{p}^{A}} C_{D}\left(\operatorname{Re}_{p}\right)
$$

By using E q. (A 8), the gas momentum equation can be arranged as

$$
\left[\left(M^{\prime \prime}\right)_{i 4}^{B}\right] \mathbf{u}_{i 4}^{B}-\left(M^{\prime \prime}\right)_{i 4}^{n} \mathbf{u}_{i 4}^{n}=\mathbf{E}_{i 4}-\mathbf{R}_{i 4}^{\prime \prime}-\mathbf{T}_{i 4}^{\prime \prime}
$$

where

$$
S_{i 4}^{\prime \prime}=\sum_{p \in i 4} N_{p}^{\prime \prime} \frac{4}{3} \pi \rho_{p}^{B}\left(r_{p}^{B}\right)^{3} \frac{\Delta t \cdot D_{p}}{1+\Delta t \cdot D_{p}}
$$




$$
\begin{gathered}
\mathbf{R}_{i 4}^{\prime \prime}=\sum_{p \in i 4} N_{p}^{\prime \prime} \frac{4}{3} \pi \rho_{p}^{B}\left[\left(r_{p}^{B}\right)^{3} \frac{\mathbf{v}_{p}^{\prime \prime}+\Delta t \cdot D_{p} \mathbf{u}_{p}^{\prime}}{1+\Delta t \cdot D_{p}}-\left(r_{p}^{\prime \prime}\right)^{3} \mathbf{v}_{p}^{\prime \prime}\right] \\
\mathbf{T}_{i 4}^{\prime \prime}=\sum_{p \in i 4} N_{p}^{\prime \prime} \frac{4}{3} \pi\left(r_{p}^{\prime \prime}\right)^{3} \mathbf{v}_{p}^{\prime \prime}\left(\rho_{p}^{B}-\rho_{p}^{\prime \prime}\right)
\end{gathered}
$$

\section{REFERENCES}

1. R. D. Reitz and F. V. Bracco, $O \mathrm{n}$ the D ependence of the Spray A ngle and $\mathrm{O}$ ther Spray Parameters on N ozzle D esign and O perating C onditions, SAE Technical Paper 790494, 1979.

2. R. D. R eitz and R. D iwakar, Structure of H igh Pressure Fuel Sprays, SAE Trans., vol. 96, sect. 5, 1987.

3. El-Beshbeeshy, M . S., H odges, J. T., and Corradini, M . L., I mage A nalysis of D iesel Sprays, SAE Technical Paper 921628, 1992.

4. Dispersion of Diesel Sprays, SAE Technical Paper 960034, 1996.

5. L. Z hang, T. Tsurushima, T. U eda, Y. Ishii, T. I tou, T. M inami, and K. Yokota, M easurement of Liquid Phase Penetration of Evaporating Spray in a DI Diesel Engine, SAE Technical Paper 971645, 1997.

6. K. R. B rowne, I. M . Partridge, and G. G reeves, Fuel Property E ffects on Fuel/A ir M ixing in a Experimental Diesel E ngine, SAE Technical Paper 8602223, 1986.

7. M . A . D. G onzales, Z. W. L ian, and R. D. Reitz, M odeling D iesel E ngine Spray Vaporization and Combustion, SAE Technical Paper 920579, 1992.

8. R. J. Priem, G. L. Borman, M . M . O. EI Wakil, A. Uyehara, and P. S. M yers, Experimental and C al culated $H$ istories of Vaporizing Fuel D rops, NACA T N 3988, 1957.

9. J. A braham and V. M agi, A M odel for M ulticomponent D roplet Vaporization in Sprays, SAE Technical Paper 980511, 1998.

10. S. A . B. A I O mari, N umerical Simulation of Transient L iquid Fuel Sprays Vaporization under Engine L ike Conditions U sing D iffusion Limit and W ell M ixed Vaporization M odels, SAE Technical Paper 960877, 1996.

11. D. Verhoeven, J. L. Vanhemelryck, and T. Baritaud, T., M acroscopic and I gnition Characteristics of H igh-Pressure Sprays of Single-C omponent Fuels, SA E Technical Paper 981069, 1998.

12. M . H ublin, P. G. G add, D. E. H all, and K. P. Schindler, E uropean Programmes on E missions Fuels and Engine Technologies (E PEFE) - Light D uty D iesel Study, SAE Technical Paper 961073, 1996.

13. Z. X. H ou, J. A braham, and D. L. Siebers, M odeling of D iesel Sprays in a Very H igh Pressure C hamber, Part II: Effects of Combustion, SA E Technical Paper 950603, 1995.

14. A. Ficarella, Sviluppo di modelli conservativi e accurati per il calcolo dei fenomeni pulsanti negli apparati di iniezione dei M CI, Ph.D . thesis, University of Bari, Bari, Italy, 1991 (in I talian).

15. C. A rcoumannis and R. J. Fairbrother, C omputer Simulation of Fuel I njection Systems for D I D iesel Engines, SAE Technical Paper 922223, 1992.

16. T. I shihara and M . O uchi, An Experimental Study on Cavitation in Unsteady F low, Bull. Jpn. Soc. Mech. Eng., no. 170, pp.354-362, 1979.

17. A. A msden, P. J. O 'Rourke, and T. D. Butler, KIVA II-A Computer Program for Chemically Reactive F lows with Sprays, L os A lamos N atl. Lab. Rep. LA-11560-M S, 1989.

18. P. J. O 'R ourke, Collective D rop Effects on Vaporizing Liquid Sprays, Ph.D. thesis, Princeton University, Princeton, N J, 1981. 
19. A. A msden, KIVA 3-A KIVA Program with Block-Structured $M$ esh for Complex $G$ eometries, L os A lamos N atl. L ab. Rep. LA -11560-M S, 1989.

20. F. G rasso and V. M agi, Modern Research Topics in Aerospace Propulsion, pp. 227-250, SpringerVerlag N ew York, N ew York, NY, 1991.

21. J. K. D ukowicz, A Particle-Fluid N umerical M odel for Liquid Sprays, J. Comput. Phys., vol. 35, No 2, pp. 229-253,1980.

22. R. D. R eitz, M odeling A tomization Processes in H igh Pressure Vaporizing Sprays, Atomization and Sprays Technol., vol. 3, pp. 309-337, 1987.

23. R. D. Reitz and F. V. Bracco, M echanism of A tomization of a Liquid Jet, Phys. Fluid, vol. 25, no. 10, 1982.

24. T. F. Su, M . A. Patterson, R. D. R eitz, and P. V. Farrel, Experimental and N umerical Studies of H igh Pressure M ultiple Injection Sprays, SA E Technical Paper 960861, 1996.

25. J. C. B eale and R. D. R eitz, M odeling Spray A tomization with the Kelvin- $H$ elmholtz/R ayleigh Taylor H ybrid M odel, Atomization and Sprays, vol. 9, pp. 623-650, 1999.

26. P. K. Senecal, Exploring Alternatives to Conventional DI Diesel Combustion Systems Using Computational F luid D ynamics, master's thesis, U niversity of W isconsin, M adison, W I, 1997.

27. Z. $H$ an and R. D. R eitz, Turbulence M odeling of I nternal Combustion E ngines U sing RN G k-E M odels, Combustion Sci. Technol., vol. 106, p. 207, 1995.

28. M . H alstead, L. K irsh, and C. Q uinn, C., The A utoignition of $H$ ydrocarbon Fuels at $H$ igh Temperature and Pressure - Fitting of a M athematical M odel, Combustion $\&$ Flame, vol. 30, pp. 45-60, 1977.

29. J. A braham, F. V. Bracco, and R. D. Reitz, Comparison of Computed and M easured Premixed C harge E ngine Combustion, Combustion Flame, vol. 60, pp. 309-322, 1985.

30. H. H iroyasu and K. N ishida, Simplified Three D imensional M odeling of M ixture Formation and Combustion in a D.I. D iesel Engine, SAE Technical Paper 890269.

31. J. N agle and R. F. Strickland-C onstable, $\mathrm{O}$ xidation of $\mathrm{C}$ arbon between $1000-2000^{\circ} \mathrm{C}$, Proc. Fifth Carbon Conf., vol. 1,pp. 154-164, Pergammon Press, London,1962.

32. A. Ficarella, D. L aforgia, G. Starace, and V. D amiani, Experimental Investigation of the Sprays of an A xi-Symmetric $\mathrm{N}$ ozzle of a Common R ail H igh Pressure E lectro-Injector, SAE Technical Paper 970054, 1997.

33. A. de Risi, T. D onateo, and D. L aforgia, D., Numerical Investigation on the Influence of Physical Parameters on Soot and $\mathrm{N}_{x}$ Engine E missions, ASME ICE-Vol. 36-2, 2001.

34. F. Payri, J. M . D esantes, and J. A rrègle, C haracterization of DI D iesel Sprays in H igh D ensity Conditions, SAE Technical Paper 960774, 1996.

35. A. Coghe and G. E. C ossali, Phase D oppler Characterization of D iesel Spray I njected in a $\mathrm{H}$ igh D ensity $\mathrm{G}$ as under Vaporization Regimes, VII Int. Symp. of Application of Laser Technology Fluid Mechanics, L isbon, Portugal, 1994.

36. H. Kosaka, T. Suzuki, and T. K amimoto, N umerical Simulation of Turbulent D ispersion of Fuel Droplets in an Unsteady Spray via Discrete Vortex M ethod, SAE Technical Paper 952433, 1995. 